\title{
Synthesis of lightweight polymer-reinforced silica aerogels with improved mechanical and thermal insulation properties for space applications
}

\author{
Hajar Maleki*, Luisa Durães, António Portugal \\ CIEPQPF, Department of Chemical Engineering, Faculty of Sciences and Technology, University of Coimbra, Rua Silvio Lima, 3030-790 Coimbra, Portugal
}

\section{A R T I C L E I N F O}

\section{Article history:}

Received 29 November 2013

Received in revised form 21 May 2014

Accepted 2 June 2014

Available online 14 June 2014

\section{Keywords:}

Silica aerogels

Hybrid materials

Alkyl/aryl-bridged silanes

Tri-methacrylate cross-linking

Nanoporous materials

\begin{abstract}
A B S T R A C T
Cross-linking of silica aerogels with organic polymers is an effective way to overcome their fragility and poor mechanical properties. It has also been shown that adjusting the nanoskeleton of silica aerogels using different silica precursors can lead to improved mechanical properties, mesoporosity and thermal conductivity. In this paper, the effect of the incorporation of 1,6-bis(trimethoxysilyl)hexane (BTMSH) and 1,4-bis(triethoxysilyl)-benzene (BTESB) into the underlying silica structure of tri-methacrylate crosslinked silica aerogels is examined. In order to attain a simple, cost and time effective procedure, the sol-gel process and addition of organic monomers are performed in one single step. The effect of the amount of silicon derived from alkyl-linked and aryl-linked bis-silane precursors as well as the effect of the cross-linker concentration on the mechanical strength, thermal conductivity, porosity and other properties of the synthesized aerogels are studied. Different reinforced silica aerogels with density range from 0.13 to $0.39 \mathrm{~g} \mathrm{~cm}^{-3}$, compression strength from 11 to $400 \mathrm{kPa}$ and thermal conductivity of 0.039 $0.093 \mathrm{~W} \mathrm{~m}^{-1} \mathrm{~K}^{-1}$ were obtained. The cross-linked aerogels made by replacing 5-10 mol\% of total silicon by BTESB showed a drastic improvement in their surface area and thermal insulation properties along with an increase in the mechanical strength. The surface area and thermal insulation improvements obtained for aryl-bridged polysiloxanes were attributed to the aryl spacer within the aerogels body, which leads to aerogel with high extent of porosity or pore volume when compared to the alkyl-bridged polysiloxanes.

Therefore, for the first time we were able to show the dependency of thermal conductivity values on the silica structure by proper designing the mesoporosity of the resulting aerogels.
\end{abstract}

(c) 2014 Elsevier Inc. All rights reserved.

\section{Introduction}

The low values of thermal conductivity, very low density, extreme porosity and high specific surface area make silica aerogels attractive materials for a number of aerospace and industrial applications [1]. Examples of these applications involve the use of silica aerogels for environment clean up and protection [2-4], battery electrodes [5], catalyst supports [6], oxygen and humidity sensors [7], aerosol particle collectors [8], space mirror protectors and others $[9,10]$. The majority of silica aerogel applications concerned the development of efficient thermal insulator materials, especially for building, aeronautical and aerospace domains [1114]. But these applications have been limited by the network fragility of silica aerogels, i.e., their weak mechanical properties.

\footnotetext{
* Corresponding author. Tel.: +351 910156 989; fax: +351 239798703.

E-mail address: hajar@eq.uc.pt (H. Maleki).
}

Therefore, in order to have silica aerogels with a wide range of applications, mechanically more robust aerogels are needed. Different approaches have been explored to improve the mechanical properties of silica aerogels [15], such as structural reinforcement using flexible silica precursors in the silica gel backbone [16-19], conformal coating of the silica backbone through cross-linking their surface with polymers [20-23], dispersing different fiber networks in the initial sol of the silica aerogel, etc. [24]. In principle, the most effective methods to improve the flexibility or elastic recovery in silica aerogels consist in the integration of organic compounds in the inorganic part of silica aerogels, resulting in hybrid silica aerogels. This can be achieved by, firstly modifying the surface chemistry of the silica network with appropriate functional groups and then growing the polymer from the modified surface. This strategy allows to produce a conformal polymer coating on the secondary silica nanoparticles and, therefore, results in the increasing of the connectivity between the silica nanoparticles, which strengthens the aerogel [11]. Until now, several polymeric 


\section{Acronyms}

AIBN 2,2'-azobis(2 methylpropionitrile)

BTMSH 1,6-bis(trimethoxysilyl)hexane

BTESB 1,4-bis(triethoxysilyl)benzene
TMOS Tetramethylorthosilicate

TMSPM 3-(trimethoxysilyl propyl) methacrylate systems, such as epoxide, polyurea, polyurethane, poly (methyl methacrylate), polyacrylonitrile and polystyrene have been applied to reinforce silica aerogels [25-28]. Such approaches lead to the development of strong silica aerogels with mechanical strength from 1.24 to $261 \mathrm{MPa}$. However, the increase of the network connectivity caused by the polymerization reactions leads to a drastic increase in the density $\left(\approx 0.5-0.8 \mathrm{~g} / \mathrm{cm}^{3}\right)$, lowering the specific surface area and, consequently, increasing the thermal conductivity [15].

In the present work, the general goal is to synthesis strong aerogels with reasonable mechanical strength, densities and thermal conductivities as low as possible in order to meet the requirement for aerospace applications. In order to compensate for the increase in the backbone thermal conductivity due to the cross-linking, we changed the microstructure pattern of the silica aerogels by cogelation of the silica backbone with the alkyl-linked bis-silane 1,6-bis(trimethoxysilyl)hexane, BTMSH, and the aryl-linked bissilane 1,4-bis(triethoxysilyl)-benzene, BTESB. Recently, Randall et al. [11] investigated the aerogels made by different alkyl-linked bis-silane precursors with different lengths of the spacer groups (bridges), in order to tailor the elastic properties of the reinforced aerogels. The purpose of this research was to promote flexibility/

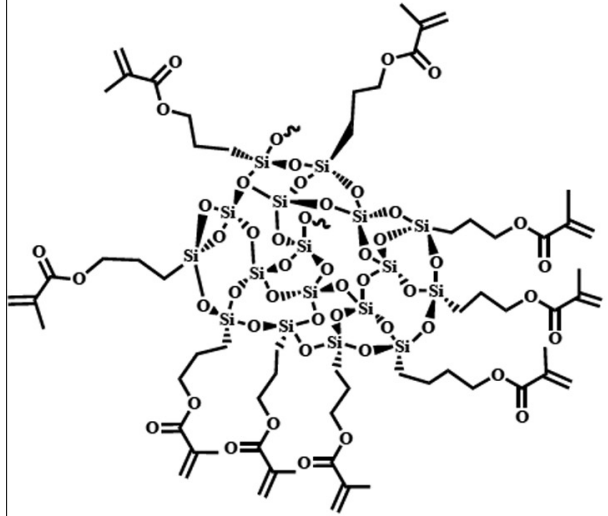

(a)

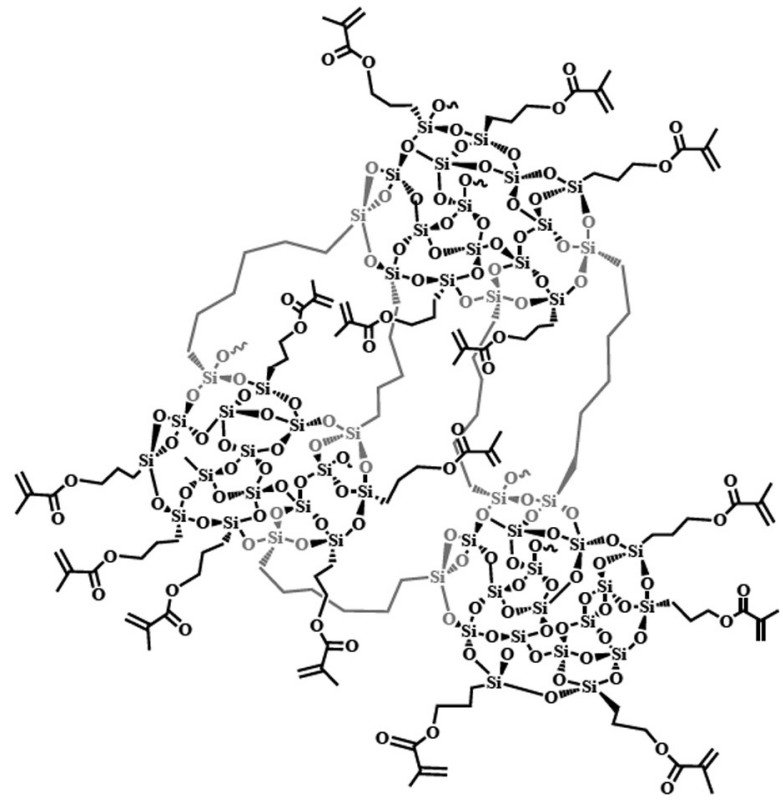

(b)

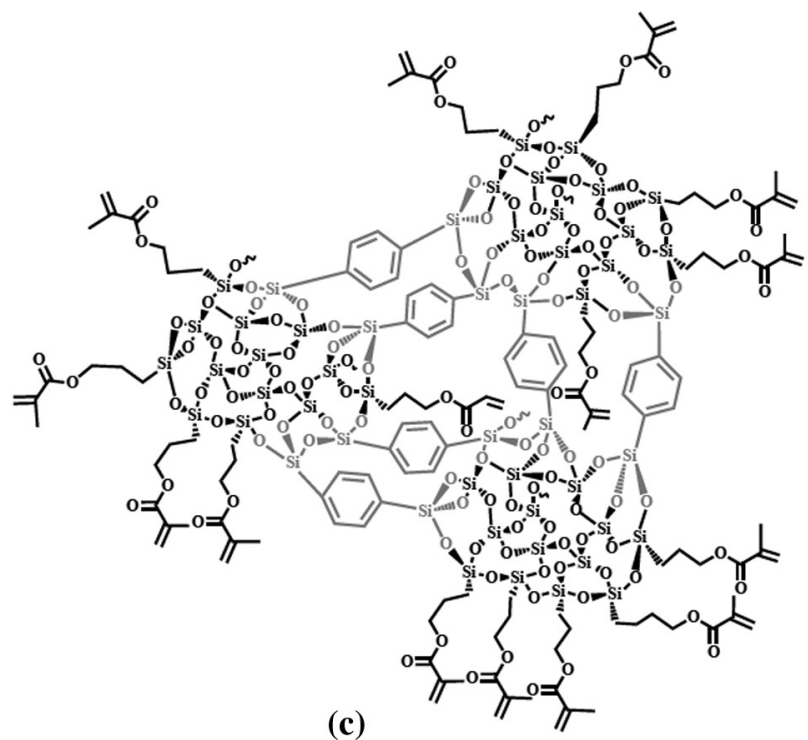

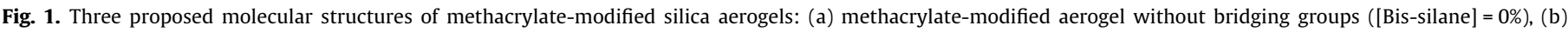

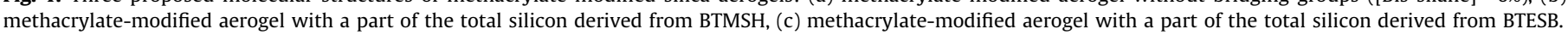


elasticity in the aerogel as well as to achieve higher compression strength by the polymer reinforcement. They indicated that the hexyl-linked bis-silane BTMSH, was the most effective of the bissilanes tested due to the results of higher mass yield and elastic recovery. However, no special attention was given to thermal conductivity of this type of aerogels. On the other hand, until now, there is no report in the literature focused in the relative merit of a bis-silane type precursor having an aryl spacer, when compared to other types of bridged bis-silane. Loy et al. and Shea et al. [2931] made extensive studies on arylene-bridged polysiloxanes and concluded that, aryl-bridged precursors lead to the aerogels with less shrinkage and therefore more controlled porosity when compared to the aerogels derived from alkyl-linked bis-silanes. However, they did not make any systematic comparative report about their mechanical and thermal insulation properties.

The particular focus of this work is the synthesis and mechanical reinforcement of silica aerogels with alkyl and aryl moieties, in order to study the role of the underlying silica backbone on the resulting properties of aerogels in a single type of polymerization.

The BTESB precursor contains a rigid aryl group that does not favour the elasticity of the aerogel. In the present work, we introduced this precursor in a very low concentration (up to $10 \mathrm{~mol} \%$ of the total silicon), in order to develop aerogels with open porous structures, which favour higher thermal insulation performance. The improvement for compression strength was obtained by polymer cross-linking. In order to react the inorganic silica backbone with an organic component (multi-functional methacrylate), we modified the surface chemistry of the silica aerogels with methacrylate-containing silica precursors, through co-condensation of core silica precursors namely TMOS (Tetramethylorthosilicate) and aryl or alkyl linked bis-silanes with TMSPM (3-(trimethoxysilyl)propyl methacrylate). Fig. 1 presents the proposed molecular structures of nonreinforced surface modified silica aerogels with the three different underlying silica structures prepared in this work.

The selected organic monomer is a multifunctional methacrylate, which can cause extensive branching and reinforcement. Therefore, an increased compressive strength of the aerogel monoliths is expected with an approximately constant overall intrinsic flexibility of the silica backbone.

Since, the tri-methacrylate cross-linker is soluble in methanol (gelation solvent), we added the organic monomer to the gelation solvent in the initial step of preparation of the sol. Then, polymerization occurs after the sol-gel process by applying post-gelation thermal treatment. Such a one pot strategy leads to a significant simplification in the synthesis of silica composites and reduced the total preparation time of silica monoliths to approximately two days, which is a drastic reduction when compared to the multistep traditional approaches to prepare isocyanate and styrene crosslinked silica aerogels $[32,33,27,34]$. Additionally, the presence of the monomer inside of silica gel monolith causes less consumption of the solvent during the post-gelation treatment, therefore to some extent leads to less energy and raw material consumption [15].

In this study, we evaluated the effect of different critical factors on some selected physicochemical properties of resulting aerogels. Such an experimental design was a starting point to understand the relation between the variations of each factor and the target properties of the silica aerogels for further exploration.

\section{Experimental}

\subsection{Materials}

Tetramethylorthosilicate ( $\geqslant 99 \% ; \quad$ TMOS), 3-(trimethoxysilyl)propyl methacrylate (98\%; TMSPM), ammonium hydroxide $\left(\mathrm{NH}_{4} \mathrm{OH} ; 28-30\right.$ wt\% solution), methanol (MeOH), ethanol (EtOH), tris[2-(acryloyloxy)ethyl]isocyanurate, 2,2'-azobis(2-methylpropionitrile) (98\%; AIBN), 1,4-bis(triethoxysilyl)-benzene (96\%; BTESB) and acetone were purchased from Aldrich. 1,6-Bis(trimethoxysilyl)hexane (98\%; BTMSH) was purchased from Cymit. All reagents were used without further purification.

\subsection{Methods}

\subsubsection{General}

Variables used in this study include the bis-silane type (BTMSH, BTESB), the mole fraction of the total silicon derived from BTMSH and BTESB (note that these precursors contribute with two silicon atoms in every molecule, and the rest of the silicon is derived from TMOS and TMSPM). By keeping the amount of silicon derived from TMSPM as $20 \mathrm{~mol} \%$ of total silicon for the whole formulation, the amount of silicon derived from BTMSH varied from 0 (named as aerogel without bridging group), to 20 and $40 \mathrm{~mol} \%$; in the aerogel derived from BTESB, the amount of silicon from this procedure had values of 0,5 and $10 \mathrm{~mol} \%$ of the total silicon.

The amount of tris[2-(acryloyloxy)ethyl] isocyanurate cross-linker (tri-methacrylate) was another variable, given as mole fraction to TMSPM. It is assumed that each tri-methacrylate cross-linker molecule reacts with the methacrylate groups of three TMSPM molecules via radical polymerization. Hence, a [Tri-meth]/ [TMSPM] molar ratio $(R)$ of 0.3 is stoichiometric, whereas ratios of 0.6 and 2 represent an excess of monomer.

For the water/total silicon mole ratio, $r$, a value of 2 is normally considered as a stoichiometric value for hydrolysis and condensation of TMOS [35]. However, an excess of water is usually needed to complete the reaction. In this study, $r$ was kept constant at a value of 4 for all formulations. Table 1 summarizes the defined parameters of this study, with their levels, and the specific nomenclature used in this paper.

\subsubsection{Preparation of polymer-reinforced silica aerogels}

To illustrate, a typical procedure is outlined for a formulation with total silicon concentration of $1.3 \mathrm{~mol} / \mathrm{L}$ in the sol, a TMSPM Si fraction of $20 \mathrm{~mol} \%$, a BTMSH Si fraction of $40 \mathrm{~mol} \%$ and the tri-methacrylate monomer in a 0.3 to 1 ratio to TMSPM (Run: B_40_R_0.3)-see Table 2 in Section 3. A solution of $1.52 \mathrm{~mL}$ $(10.56 \mathrm{mmol})$ of TMOS, $1.74 \mathrm{~mL}(10.56 \mathrm{mmol})$ of BTMSH, and $1.23 \mathrm{~mL}(5.2 \mathrm{mmol})$ of TMSPM was cooled to below $0{ }^{\circ} \mathrm{C}$ in an ethanol mixed dried-ice bath (Solution 1 ). Solution 2 was prepared by adding $12.9 \mathrm{~mL}$ of gelation solvent (methanol), $0.73 \mathrm{~g}$ of tris[2(acryloyloxy)ethyl] isocyanurate monomer, $1.9 \mathrm{~mL}$ of $\mathrm{H}_{2} \mathrm{O}(r=4)$, $0.7 \mathrm{~mL}$ of $\mathrm{NH}_{4} \mathrm{OH}$ and $0.07 \mathrm{~g}$ of AIBN (formulated to $10 \mathrm{wt} \%$ of the organic monomer). The two solutions were mixed and poured into two propylene cylindrical molds, nominally with $17.2 \mathrm{~mm}$ in diameter. The gels were formed within $5 \mathrm{~min}$ to $2 \mathrm{~h}$ depending on the formulation. After aging for $24 \mathrm{~h}$, the wet gel was demolded

Table 1

Synthesis parameters of reinforced silica aerogels.

\begin{tabular}{lll}
\hline Parameters & Levels & Nomenclature \\
\hline Bis-silane types & BTMSH & B \\
& BTESB & Bz \\
R = [Tri-meth]/[TMSPM] Molar ratio & - & Nb \\
& 0.3 & R_0.3 \\
[BTMSH] Si mol\% & 0.6 & R_0.6 \\
& 2 & R_2 \\
[BTESB] Si mol\% & $0 \%$ & Nb \\
& $20 \%$ & B_20 \\
& $40 \%$ & B_40 \\
& $0 \%$ & Nb \\
& $5 \%$ & Bz_5 \\
\end{tabular}


Table 2

Measured properties of polymer reinforced aerogels.

\begin{tabular}{|c|c|c|c|c|c|}
\hline Sample & $\begin{array}{l}\text { Density } \\
\left(\mathrm{g} \mathrm{cm}^{-3}\right)\end{array}$ & $\begin{array}{l}\text { Shrinkage } \\
\text { (Diam.\%) }\end{array}$ & $\begin{array}{l}\text { Average } \\
\text { elastic } \\
\text { modulus } \\
(\mathrm{kPa})\end{array}$ & $\begin{array}{l}\text { Thermal } \\
\text { conductivity } \\
\left(\mathrm{W} \mathrm{m} \mathrm{m}^{-1} \mathrm{~K}^{-1}\right)\end{array}$ & $\begin{array}{l}\text { Average } \\
\text { max. } \\
\text { stress at } \\
\text { break } \\
(\mathrm{kPa})\end{array}$ \\
\hline \multirow[t]{2}{*}{ Nb_R_0.3 } & 0.173 & 9 & 1.73 & 0.044 & 22.8 \\
\hline & 0.189 & 10 & & 0.046 & \\
\hline \multirow[t]{2}{*}{ Nb_R_0.6 } & 0.183 & 12 & 0.93 & 0.0548 & 137.0 \\
\hline & 0.187 & 18 & & 0.0512 & \\
\hline \multirow[t]{2}{*}{$\mathrm{Nb} \_R \_2$} & 0.290 & 17 & 3.33 & 0.0938 & 257.0 \\
\hline & 0.240 & 20 & & 0.0925 & \\
\hline \multirow[t]{2}{*}{ B_20_R_0.3 } & 0.141 & 5 & 0.95 & 0.044 & 25.0 \\
\hline & 0.162 & 8 & & 0.047 & \\
\hline \multirow[t]{2}{*}{ B_20_R_0.6 } & 0.197 & 8 & 0.93 & 0.052 & 32.2 \\
\hline & 0.188 & 11 & & 0.050 & \\
\hline \multirow[t]{2}{*}{ B_20_R_2 } & 0.271 & 14 & 6.77 & 0.053 & 400.0 \\
\hline & 0.314 & 12 & & 0.053 & \\
\hline \multirow[t]{2}{*}{ B_40_R_0.3 } & 0.220 & 14 & 2.74 & 0.065 & 213.0 \\
\hline & 0.213 & 12 & & 0.067 & \\
\hline \multirow[t]{2}{*}{ B_40_R_0.6 } & 0.220 & 11 & 2.27 & 0.067 & 248.0 \\
\hline & 0.192 & 14 & & 0.068 & \\
\hline \multirow[t]{2}{*}{ B_40_R_2 } & 0.390 & 15 & 5.96 & 0.089 & 270.0 \\
\hline & 0.330 & 16 & & 0.085 & \\
\hline \multirow[t]{2}{*}{ Bz_5_R_0.3 } & 0.129 & 6 & 1.11 & 0.039 & 17.7 \\
\hline & 0.143 & 10 & & 0.042 & \\
\hline \multirow[t]{2}{*}{ Bz_5_R_0.6 } & 0.144 & 11 & 1.17 & 0.039 & 87.8 \\
\hline & 0.149 & 15 & & 0.043 & \\
\hline \multirow[t]{2}{*}{ Bz_5_R_2 } & 0.314 & 13 & 5.42 & 0.051 & 131.0 \\
\hline & 0.318 & 13 & & 0.053 & \\
\hline \multirow[t]{2}{*}{ Bz_10_R_0.3 } & 0.167 & 12 & 1.44 & 0.039 & 10.7 \\
\hline & 0.163 & 12 & & 0.038 & \\
\hline \multirow[t]{2}{*}{ Bz_10_R_0.6 } & 0.179 & 14 & 0.74 & 0.049 & 78.7 \\
\hline & 0.175 & 13 & & 0.048 & \\
\hline \multirow[t]{2}{*}{$\mathrm{Bz} \_10 \_R \_2$} & 0.250 & 10 & 3.61 & 0.050 & 279.0 \\
\hline & 0.295 & 12 & & 0.054 & \\
\hline
\end{tabular}

and placed in a cylindrical reaction flask, containing enough ethanol solvent to cover the gel and the same concentration of initiator used in the gelation step. The sample was refluxed at $70{ }^{\circ} \mathrm{C}$, for $6 \mathrm{~h}$, to promote free radical polymerization of organic monomers inside the pores of the wet gel with silica surface functionalities. After cross-linking, in order to remove residual water and ethanol, the samples were washed three times with the gelation solvent, giving an $8 \mathrm{~h}$ interval between each washing step, and, then the cylindrical wet gels were placed carefully in a cylindrical supercritical fluid extraction chamber. In this step, before drying with supercritical $\mathrm{CO}_{2}$, the samples were washed with methanol in order to guarantee the purification of monoliths. Unreacted silica precursors and organic residues were eliminated by passing the solvent through the monoliths for $1 \mathrm{~h}$ with a mass flow rate of $2 \mathrm{~mL} / \mathrm{min}$ and a chamber pressure of 200 bar under constant temperature of $40{ }^{\circ} \mathrm{C}$. Then, the samples were exposed to the flow of supercritical $\mathrm{CO}_{2}$ for $90 \mathrm{~min}$, having a mass flow rate of $5 \mathrm{~mL} / \mathrm{min}$ and a $\mathrm{CO}_{2}$ volume of $51 \mathrm{~L}$ (STP).

\subsubsection{Preparation of nonreinforced silica aerogels}

The nonreinforced aerogel for the same proportion of silica precursors was prepared following the similar procedure to that described above. In this case, the addition of the monomer and radical initiator to the Solution 2, as well as the polymerization reaction step were eliminated. After the gelation of the samples and $24 \mathrm{~h}$ aging, they were demolded and washed three times with the methanol. After, the wet gels were dried using supercritical $\mathrm{CO}_{2}$ fluid extraction under the conditions explained for their reinforced counterparts. Fig. 2 presents briefly the whole chemical procedure to develop cross-linked and non-cross-linked aerogels.

\subsection{Characterization techniques}

Solid ${ }^{29} \mathrm{Si}$ and ${ }^{13} \mathrm{C}$ NMR spectra of the aerogels were obtained by using an Inova 500 spectrometer using a $4 \mathrm{~mm}$ solids probe with cross-polarization and magic angle spinning at $11 \mathrm{kHz}$.

The bulk density $\left(\rho_{\mathrm{b}}\right)$ was determined by measuring the weight and volume of the sample. Dimensional shrinkage (\%) is taken as the difference between the diameters of the aerogel monolith

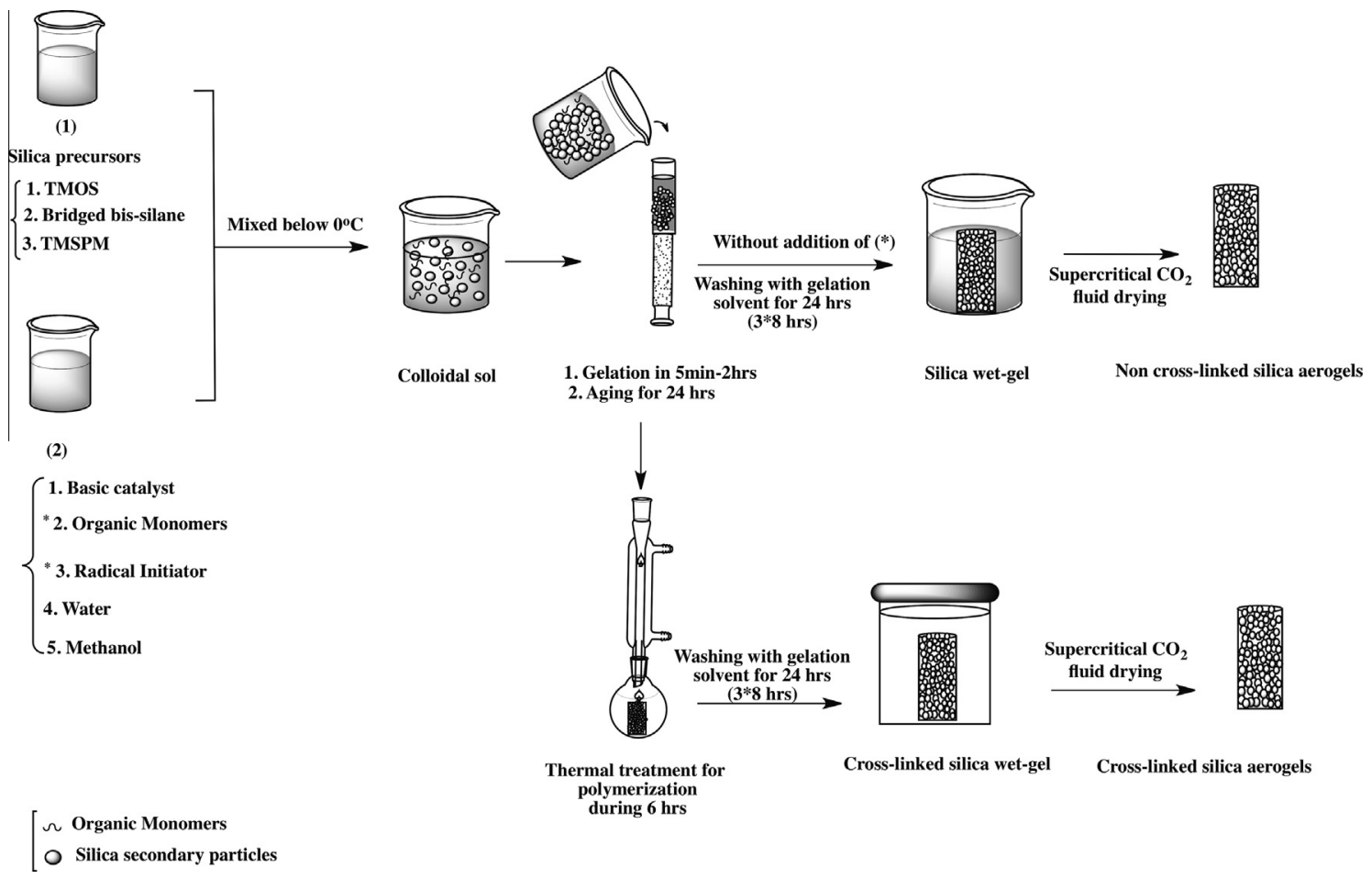

Fig. 2. Practical approach to the synthesis of polymer-reinforced and nonreinforced silica aerogels. 
and of the $20 \mathrm{~mL}$ syringe mold (nominally $17.2 \mathrm{~mm}$ ). He picnometry (Accupyc 1330, Micromeritics) was used to measure the real (skeleton) density of the samples. Combining the information of the skeleton and bulk densities, it is possible to evaluate the porosity of the samples. In addition, we used the Nitrogen gas adsorption (Accelerated Surface Area and Porosimetry ASAP 2000, Micromeritics) for determination of the specific surface area, pore size distribution, pore surface area and pore volume of the material. Before the analysis, the sample was outgassed at $60^{\circ} \mathrm{C}$ in vacuum $\left(10^{-5}\right.$ bar) during $24 \mathrm{~h}$, to remove adsorbed species. In the analysis, volumes of the adsorbed nitrogen at five different relative pressures $(0.05$ to 0.2$)$ were taken at $77 \mathrm{~K}$, to obtain the specific surface area by the BET theory. The desorption isotherm and the BJH theory were used for the porosimetry measurements.

Scanning electron microscopy (SEM) (JMS-5310, JOEL) was used to observe the materials microstructure. Due to the low electrical conductivity of the highly porous silica-based samples, an Au film was deposited on their surface, using the PVD (Physical Vapor Deposition) technique during $20 \mathrm{~s}$.

For transmission electron microscopy (TEM), the specimens have been prepared by cleaving a small section with a razor blade, and then attaching this section to a copper-mesh TEM grid. Grids were visualized with a microscope (JEOL JEM 1400), operated at $120 \mathrm{kV}$. Much of the specimens were too thick for analysis, but the thin edges were electron transparent.

The thermal conductivity of the reinforced aerogels was measured using a transient method (Thermal constants analyzer TPS 2500 S, Hot Disk). The sensor is clamped between two identical disc shaped pieces of the sample, which have a diameter of $1 \mathrm{~cm}$ and thickness of $0.5 \mathrm{~cm}$ (properly cut from the cylindrical aerogel samples). This analysis was carried out at $20^{\circ} \mathrm{C}$ and the equipment presents a reproducibility and accuracy over $1 \%$ and $5 \%$, respectively.

Thermal gravimetric analysis (TGA) was performed using a TA model TGA-Q500 instrument with a heating rate of $10^{\circ} \mathrm{C} \mathrm{min}-1$, from room temperature to $600{ }^{\circ} \mathrm{C}$ in a nitrogen atmosphere. This equipment allowed the evaluation of the weight contribution of the cross-linker in the materials. In addition, a simultaneous differential thermal analyzer (SDT), SDT-Q600, from TA, was used to obtain the complementary DSC curves, in order to better discuss the nature of the thermal phenomena (endothermic or exothermic). The analyses in this equipment had the same operation conditions as the TGA analyses.

For the mechanical test, samples were cut with dimensions ratio of 2:1 (length: diameter), and were polished to make sure that top and bottom side were smooth and parallel. The compression test was conducted following the ASTM standard D695-02a. All tests were done at nominal room conditions with a stroke speed of $1.3 \mathrm{~mm} / \mathrm{min}$.

\section{Results and discussion}

Resulting properties of the synthesized polymer-reinforced and nonreinforced aerogels monoliths under different preparation conditions are presented in Tables 2 and 3, respectively.

For each formulation in Table 2, two independent replicates were performed, and the density and thermal conductivity of all obtained aerogels were measured. Comparing the results shown in Table 2 with those on Table 3, it can seen that the density in the aerogels has been influenced by the type and concentration of the bis-silane as well as by the cross-linker concentration (in the reinforced aerogels).

Mechanical strength of aerogels was improved by introducing bis-silane precursors for the reinforced (Table 2) and nonreinforced (Table 3) materials. It can also be seen that cross-linked aerogels have improved in terms of structural integrity (or mechanical
Table 3

Measured properties of nonreinforced aerogels.

\begin{tabular}{llllll}
\hline Sample & $\begin{array}{l}\text { Density } \\
\left(\mathrm{g} \mathrm{cm}^{-3}\right)\end{array}$ & $\begin{array}{l}\text { Shrinkage } \\
(\text { Diam.\%) }\end{array}$ & $\begin{array}{l}\text { Average } \\
\text { Elastic } \\
\text { Modulus } \\
(\mathrm{kPa})\end{array}$ & $\begin{array}{l}\text { Thermal } \\
\text { Conductivity } \\
\left(\mathrm{W} \mathrm{m}^{-1} \mathrm{~K}^{-1}\right)\end{array}$ & $\begin{array}{l}\text { Average } \\
\text { Max. Stress } \\
\text { at break } \\
(\mathrm{kPa})\end{array}$ \\
\hline $\mathrm{Nb}$ & $\approx 0.243$ & 28 & $-^{\mathrm{a}}$ & $-^{\mathrm{b}}$ & $-^{\mathrm{a}}$ \\
$\mathrm{B} \_20$ & 0.192 & 15 & 1.98 & 0.050 & 32.1 \\
$\mathrm{~B}$ 40 & 0.185 & 10 & 1.68 & 0.057 & 10.0 \\
Bz_10 & 0.145 & 20 & $--^{\mathrm{a}}$ & 0.051 & $-^{\mathrm{a}}$ \\
\hline
\end{tabular}

a Samples are too fragile for measurement of this property.

b Samples lose their monolithic structure, which hinders the measurement of their thermal conductivity.

properties) compared to the nonreinforced counterparts. Basically, in terms of BTMSH based aerogels and aerogels without bridgedbis-silane precursor in their underlying silica structure, the mechanical properties improvement always is accompanied by an increase in the network connectivity and, consequently, an increase in the density and thermal conductivity. While, in terms of BTESB based aerogels with comparable density, it has been found that despite of macroscopic and microscopic mechanical strength improvement upon cross-linking, the initial thermal insulation performance of native aerogels has been retained or, in most of cases, to some extent has been even improved. Therefore, this observation suggests the profound influence of the type of underlying silica and cross-linker on the aforementioned properties.

A deeper discussion of these results is carried out in the next sections.

\subsection{Chemical characterization}

The chemical structures of prepared reinforced and nonreinforced silica aerogels have been confirmed by solid ${ }^{29} \mathrm{Si}$ NMR and ${ }^{13} \mathrm{C}$ NMR. Fig. 3 shows the proposed cross-linking strategies for obtaining the silica aerogels of this study as well as the schematic expected chemical structures.

Solid ${ }^{29} \mathrm{Si}$ NMR spectra of selected reinforced aerogel samples are shown in Fig. 4, along with that for the sample prepared from plain TMOS only. As shown in Fig. 4a, TMOS-derived silicons appear at $-110 \mathrm{ppm}\left(\mathrm{Q}_{4}\right.$, small peak), $-100 \mathrm{ppm}\left(\mathrm{Q}_{3}\right)$ and $-95 \mathrm{ppm}\left(\mathrm{Q}_{2}\right)$, which correspond to the formation of four, three and two Si-O-Si bridges, respectively [25]. Fig. $4 \mathrm{~b}$ shows the spectrum for monoliths without BTMSH or BTESB. Two broad peaks are observed for TMSPM-derived silicon, a peak at $-69 \mathrm{ppm}$ ( $\mathrm{T}_{3 \mathrm{M}}$ peak) and at $-61 \mathrm{ppm}\left(\mathrm{T}_{2 \mathrm{M}}\right.$ peak). The peak $\mathrm{T}_{2 \mathrm{M}}$ integrates about half of the area of the peak $\mathrm{T}_{3 \mathrm{M}}$, indicating that $2 / 3$ of TMSPM silicon atoms had completely reacted. Spectrum of Fig. 4c belongs to the silica aerogels with $40 \mathrm{~mol} \%$ of silicon derived from BTMSH. In this spectrum, the three broad additional peaks are due to the silicon derived from BTMSH groups. Fully reacted BTMSH derived silicon $\left(\mathrm{T}_{3 \mathrm{~B}}\right)$ appears at $-67 \mathrm{ppm}$, while the $\mathrm{T}_{2 \mathrm{~B}}$ peak appears at $-58 \mathrm{ppm}$ and the $\mathrm{T}_{1 \mathrm{~B}}$ appears at $-49 \mathrm{ppm}$ [34]. Due to the strong overlapping of $T_{3 B}$ and $T_{2 B}$ peaks with $T_{3 M}$ and $T_{2 M}$, it is difficult to figure out the extent of reaction of the silicon atoms for BTMSH. However, assuming the same extent of reaction for TMSPM as spectra $b$ and subtracting the $\mathrm{T}_{3 \mathrm{M}}, \mathrm{T}_{2 \mathrm{M}}$, it can be deduced that the area of the $T_{2 B}$ peak is to some extent larger than $T_{3 B}$. Therefore, it can be concluded that more than half of BTMSH silicon atoms are not fully reacted. Fig. 4d, shows the spectrum for monoliths with $10 \mathrm{~mol} \%$ of silicon atoms derived from BTESB. Two broad and low intense peaks are observed for BTESB-derived silicons, a peak at $-78 \mathrm{ppm}\left(\mathrm{T}_{3 \mathrm{Bz}}\right)$ and other at $-71 \mathrm{ppm}\left(\mathrm{T}_{2 \mathrm{Bz}}\right)[36]$. The $\mathrm{T}_{2 \mathrm{Bz}}$ peak is strongly overlapped with the $\mathrm{T}_{3 \mathrm{M}}$ and has slightly larger peak 


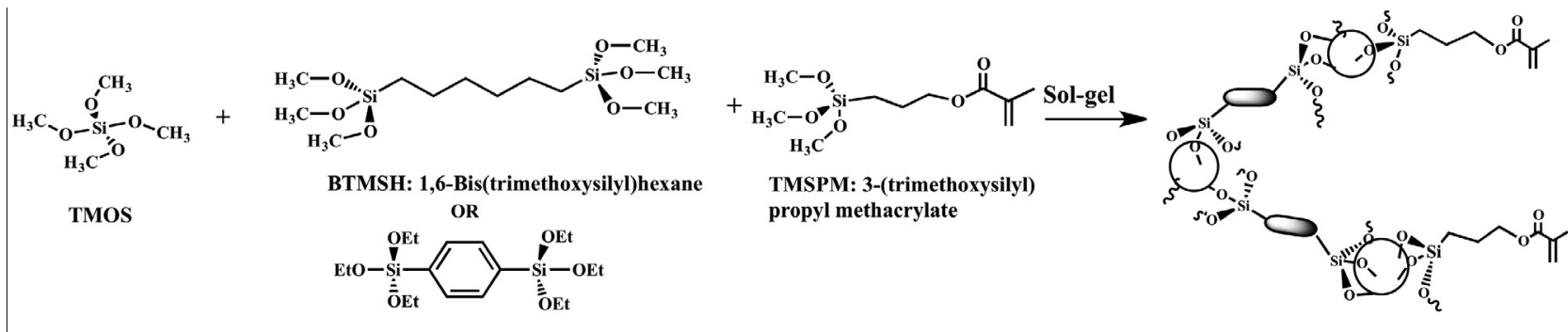

BTESB: 1,4-Bis(triethoxysilyl)-benzene

Non-crosslinked silica wet gel

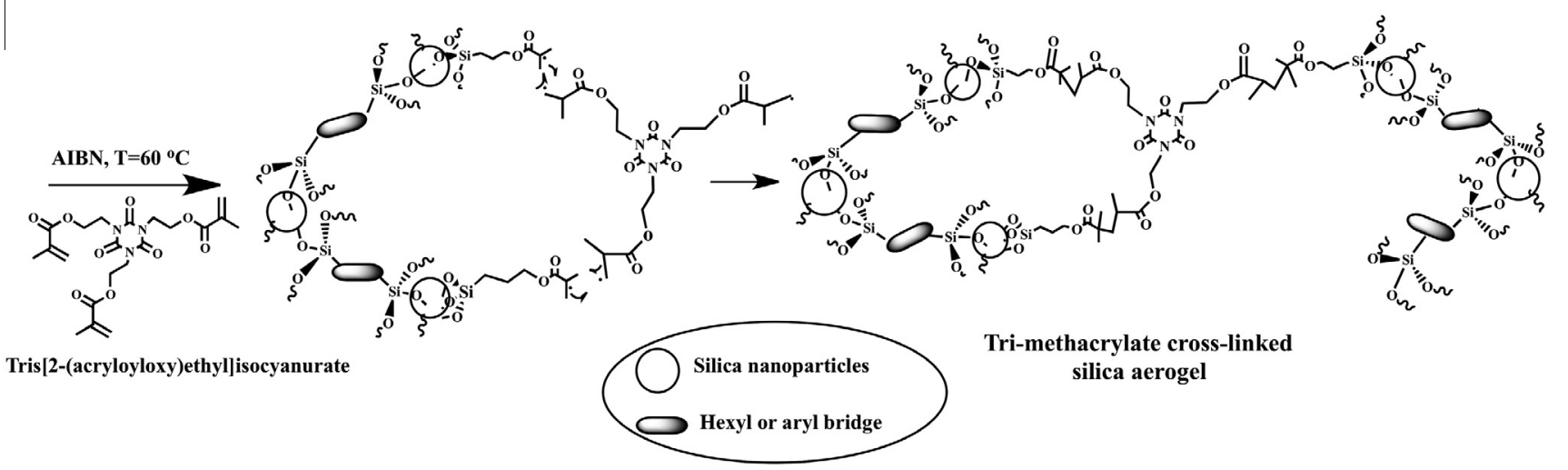

Fig. 3. Proposed cross-linking reaction for silica aerogels with different underlying silica structures.
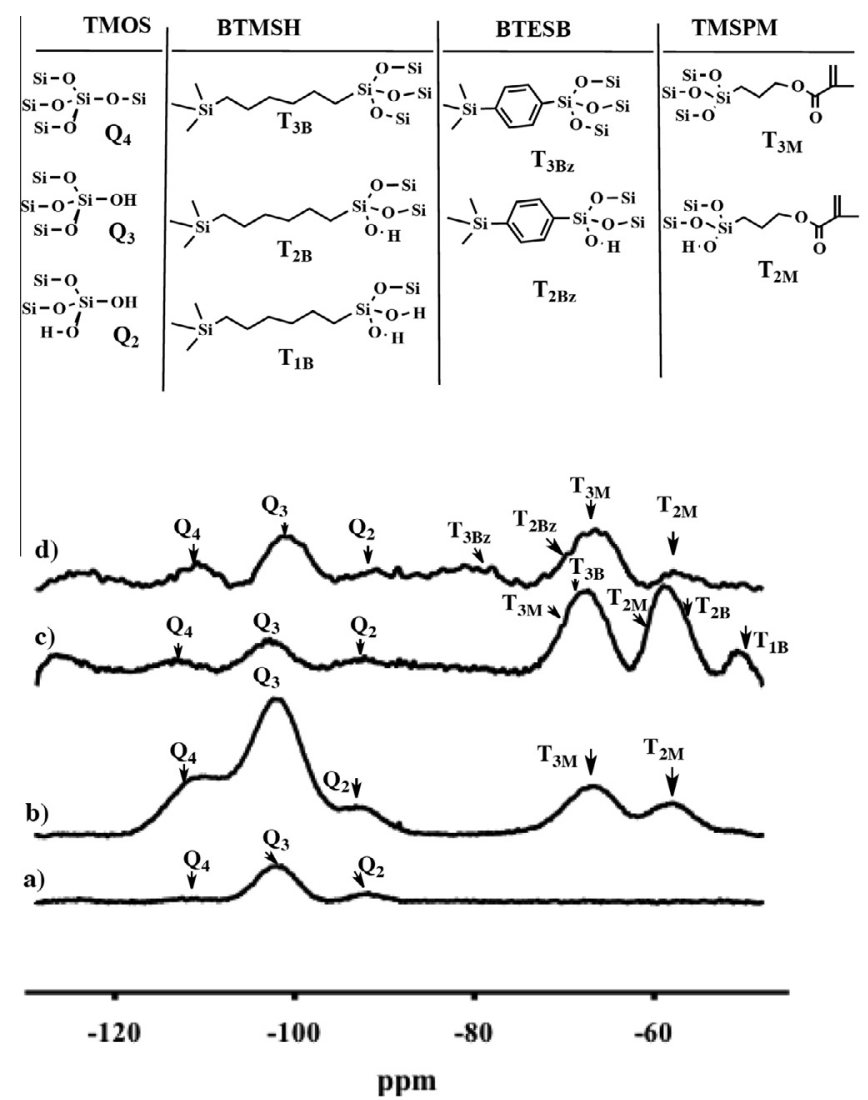

Fig. 4. Solid ${ }^{29} \mathrm{Si}$ NMR spectra of aerogel samples formulated from (a) TMOS alone, (b) Non-X-TMOS $80 \mathrm{~mol} \%$ + TMSPMA $20 \mathrm{~mol} \%$ (Nb), (c) Non-X-TMOS $40 \mathrm{~mol} \%$ + BTMSH $40 \mathrm{~mol} \%$ + TMSPMA $20 \mathrm{~mol} \% \quad$ (B_40), (d) Non-X-TMOS $70 \mathrm{~mol} \%$ + BTESB $10 \mathrm{~mol} \%$ + TMSPMA 20 mol\% (Bz_10), (X = cross-linked).

area than $\mathrm{T}_{3 \mathrm{Bz}}$, which indicates a non-complete reaction of BTESB within the aerogel monoliths.

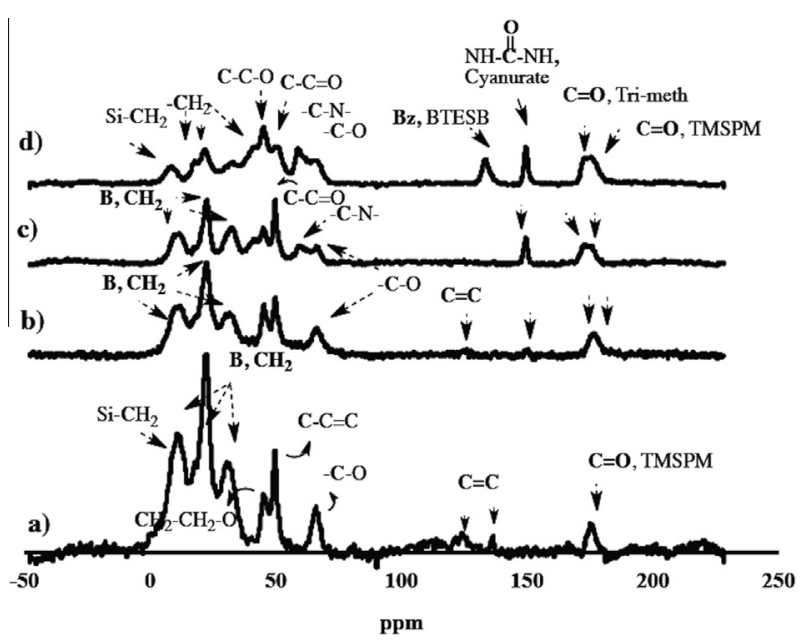

Fig. 5. Solid ${ }^{13} \mathrm{C}$ NMR spectra of aerogel samples (a) B_40, (b) B_40_R_0.3, (c) B_40_R_2 and (d) Bz_10_R_2.

Representative solid ${ }^{13} \mathrm{C}$ NMR spectra of selected prepared aerogels are shown in Fig. 5a-d. The spectrum of Fig. 5a belongs to the nonreinforced silica aerogels prepared with $40 \mathrm{~mol} \%$ of silicon derived from BTMSH. The broad peaks at $121 \mathrm{ppm}, 134 \mathrm{ppm}$ and $174 \mathrm{ppm}$ belong to the aliphatic double bond and carbonyl bonds of silica surface methacrylate group derived from TMSPM. The methylene groups from hexyl link of BTMSH appear at 12, 22, 32 ppm (Fig. 5b and c), which are masked with other aliphatic carbon due to the polymerization. Fig. $5 \mathrm{~b}$ and $\mathrm{c}$ belong to the formulations with the same underlying silica as in the spectrum of Fig. 5a, but with cross-linking with tri-methacrylate, using $R=0.3$ and $R=2$, respectively. As it is clear, the aliphatic carbon double bonds due to the silica surface methacrylate disappear in both spectra. Instead, a peak at $150 \mathrm{ppm}$ and the intense and overlapped peak at $171 \mathrm{ppm}$, due the insertion of cyanurate groups and the carbonyl bond of tri-methacrylate monomer, show up. However, 
Table 4

Water contact angles of selected nonreinforced and reinforced aerogels.

\begin{tabular}{llll}
\hline Bis-silane & \multicolumn{4}{l}{ Water contact angle $\left(^{\circ}\right)$} \\
\cline { 2 - 4 } & $R \_0$ & $R \_0.3$ & $R \_2$ \\
\hline $\mathrm{Nb}$ & 0 & $30 \pm 7$ & 0 \\
$\mathrm{Bz} \_10$ & $130 \pm 5$ & $90 \pm 8$ & $66 \pm 6$ \\
$\mathrm{~B} \_40$ & $139 \pm 3$ & $102 \pm 2$ & $76 \pm 5$ \\
\hline
\end{tabular}

the spectrum at Fig. $5 b$ indicates that the reinforced aerogel with $R=0.3$, due to the lower addition of cross-linker to the silica surface, still has some unreacted carbon double bonds and the intensity of the characteristic peak of cyanurate is very low. In Fig. $5 c$ the carbon double bonds were totally reacted and the peak area of cyanurate is four times higher than the corresponding peak area at Fig. 5b.

Fig. $5 \mathrm{~d}$ belongs to the cross-linked aerogel with $R=2$ and $10 \mathrm{~mol} \%$ of silicon derived from BTESB. In this spectrum, with full reaction of aliphatic carbon double bonds, the peak at $135 \mathrm{ppm}$ is the evidence of the insertion of aryl group of BTESB to the aerogels. The peak area of the cyanurate group in this figure is about 1.5 times higher than the peak area of same group in the spectrum of Fig. 5c. Therefore, it can be proved that, comparing with aerogel samples with $40 \%$ BTMSH in their underlying silica network, the extent of polymerization for the aerogel sample with $10 \mathrm{~mol} \%$ of silicon from BTESB is relatively high. Due to the lower introduced amount of BTESB (maximum 5-10 mol\% of silicon in each formulation) into the aerogel and its rigid nature, less steric hindrance and less possible masking of silica surface functionality exists in such an aerogel. Therefore, high accessibility of surface methacrylate groups leads them to react easily with the cross-linker and, consequently, a higher extent of polymerization occurs. Finally, the peak at $65 \mathrm{ppm}$ for all spectra might be due to the presence of residual methoxy groups during the incomplete hydrolysis of silica precursors.

Hydrophobic/hydrophilic properties of some selected samples were evaluated by studying their water contact angles. Table 4 presents the measured values for samples without bis-silane along with samples containing $10 \%$ and $40 \mathrm{~mol} \%$ of silicon derived from BTESB and BTMSH at given $R$ values ( 0.3 and 2 ), respectively. Basically, the native TMOS-derived aerogels of this study, upon exposure to water, tend to interact promptly with water molecules and decompose thoroughly. However, by surface functionalization of this aerogels or/and cross-linking with tri-methacrylate, this effect has been slightly improved; after dispensing the water droplets on the surface, they tend to make holes instead of the total decomposition of the silica aerogel.

As expected, underlying silica has a major contribution on the hydrophobic nature of the prepared aerogels. This can be confirmed by the high contact angle for nonreinforced BTMSH $\left(139^{\circ}\right)$ and BTESB $\left(130^{\circ}\right)$ derived gels, which indicates that the hexyl and aryl groups are present in the surface and contribute to the hydrophobic nature of the aerogels. Apart from the underlying silica effect, the effect of $R$ values on the contact angle of the reinforced aerogels also is pronounced, indicating that the crosslinker of this study somehow suppresses the surface hydrophobicity upon coating the silica particles surface. However, despite of the cross-linker interaction with water, the contact angle measured here for the reinforced BTMSH derived aerogel (B_40_R_0.3) is in good agreement with the contact angle of styrene reinforced aerogels containing BTMSH precursors [34].

\subsection{Physical and microstructural characterization}

\subsubsection{Density, porosity and dimensional changes}

Fig. 6a shows the bulk density changes for tri-methacrylate cross-linked and non-cross-linked aerogels with 0-40 mol\% Si from BTMSH and 5-10 mol\% Si from BTESB versus the [tri-methacrylate]/[TMSPM] molar ratio. From this figure, as expected, with increasing molar concentration of tri-methacrylate monomers, the density increases, especially at a higher concentration of BTMSH due to the insertion of additional mass of hexyl groups. At the lowest concentration of tri-methacrylate monomer, due to the little incorporation of cross-linker in the aerogels, almost similar densities are obtained for non-cross-linked and cross-linked aerogels. Porosity always follows the opposite trend of density and it is calculated by Eq. (1) from the measured bulk density $\left(\rho_{\mathrm{b}}\right)$ and the skeletal density $\left(\rho_{\mathrm{s}}\right)$, being the second measured by helium pycnometry.

Porosity $(\%)=\left(\frac{1}{\rho_{\mathrm{b}}}-\frac{1}{\rho_{\mathrm{s}}}\right) /\left(\frac{1}{\rho_{\mathrm{b}}}\right) \times 100$

The results of skeletal density $\left(\rho_{\mathrm{s}}\right)$ and measured porosity of representative reinforced and nonreinforced aerogel samples are indicated in Table 5.

Considering Eq. (1), the cross-linked samples of this study have relatively open structure, for instance, the typical reinforced aerogel with average bulk density of $\rho_{\mathrm{b}}=0.390 \mathrm{~g} \mathrm{~cm}^{-3}$ has $71 \%$ porosity, whereas with same underlying silica, the nonreinforced aerogel with average density of $\rho_{\mathrm{b}}=0.185 \mathrm{~g} \mathrm{~cm}^{-3}$ is $85 \%$ porous. Examining the porosity of some selected samples, it can be concluded that the porosity decreases with increasing molar concentrations of both BTMSH and tri-methacrylate cross-linker. Both density and porosity of aerogels are a consequence of the dimensional shrinkage of the aerogel during the drying and processing steps. As indicated in Fig. 6b and Tables 2 and 3, all the aerogels of this study present a dimensional shrinkage, from $6-18 \%$ for reinforced aerogels and $10-31 \%$ for nonreinforced aerogels. Though there is no regular trend between the dimensional shrinkage and the synthesis parameters of the aerogels under study, it has been shown that altering the silica backbone with bridged precursors leads to less shrinkage. Basically, introducing the non-polar alkyl and aryl bridged bis-silane precursors and the surface methacrylate groups
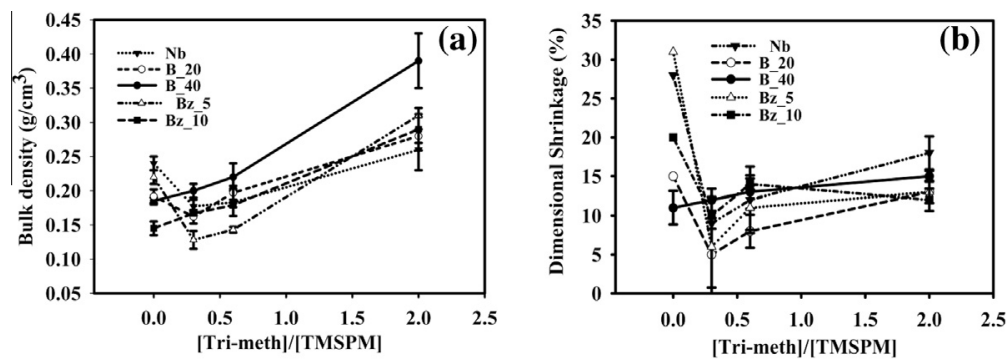

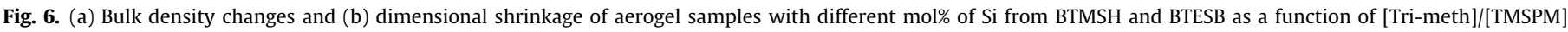
molar ratio. 
Table 5

Surface area, porosity, skeletal density $\left(\rho_{\mathrm{s}}\right)$, pore volume and average pore size values for representative nonreinforced and reinforced samples.

\begin{tabular}{llllll}
\hline Sample & $\begin{array}{l}\text { BET } \\
\text { surface } \\
\text { area } \\
\left(\mathrm{m}^{2} \mathrm{~g}^{-1}\right)\end{array}$ & $\begin{array}{l}\text { Average } \\
\text { pore } \\
\text { diameter } \\
(\mathrm{nm})\end{array}$ & $\begin{array}{l}\text { Pore } \\
\text { volume } \\
\left(\mathrm{cm}^{3} \mathrm{~g}^{-1}\right)\end{array}$ & $\begin{array}{l}\text { Porosity } \\
(\%)\end{array}$ & $\begin{array}{l}\rho_{\mathrm{s}} \\
\left(\mathrm{g} \mathrm{cm}^{-3}\right)\end{array}$ \\
\hline Nb & 854.9 & 4.9 & 1.44 & 91 & 2.78 \\
Nb_R_0.3 & 481.3 & 10.1 & 1.33 & 86 & 1.28 \\
Nb_R_2 & 178.8 & 9.2 & 0.43 & 77 & 1.08 \\
B_40 & 203.6 & 7.5 & 0.51 & 85 & 1.23 \\
B_40_R_0.3 & 249.0 & 9.2 & 0.50 & 87 & 1.69 \\
B_40_R_0.6 & 82.2 & 7.8 & 0.27 & 84 & 1.25 \\
B_40_R_2 & 7.0 & 6.4 & 0.01 & 71 & 1.20 \\
Bz_10 & 719.0 & 9.1 & 1.41 & 93 & 2.07 \\
Bz_10_R_0.3 & 710.0 & 10.7 & 0.71 & 89 & 1.50 \\
Bz_10_R_2 & 208.9 & 13.1 & 0.68 & 86 & 1.92 \\
\hline
\end{tabular}

into the nonreinforced aerogels leads to a decrease in the shrinkage. In fact, creation of silica surface with lack of Si-OH groups by introducing alkyl/aryl bis-silane precursors and more importantly by surface methacrylate functionality makes these groups repel each other causing less shrinkage during the drying stage. However, for reinforced samples, the shrinkage of the aerogels is influenced by both the introduction of bridged bis-silanes and the concentration of the cross-linker. For instance, the sample with $0 \%$ of bridged precursor and a $R$ value of 2 exhibits higher shrinkage during the course of drying and processing, which means that alkyl and aryl linked bis-silane to some extent decrease the shrinkage. In the other hand, for samples with the same underlying silica backbone, increasing the cross-linker concentration leads to an increase of the dimensional shrinkage. This is likely due to the type of the multifunctional cross-linker on the silica surface, which due to the high extent of polymerization and consequent steric hindrance, leads to less spring back to the original dimension of the aerogel.
Representative cross-linked aerogels of the whole samples made in this study are shown in Fig. 7. More transparent aerogels could be prepared with lower concentration of bridged bis-silanes and less extent of polymerization. But, stronger aerogels with high structural integrity, handling and processing capability can be obtained when higher extent of polymerization occurs on the silica surface.

\subsubsection{Micro and mesoporous structures of the developed aerogels}

The porous nature of representative nonreinforced and reinforced aerogels was evaluated by nitrogen physisorption measurements. The details of pore size, pore volume and specific surface area of the aerogels are presented at Table 5. Representative isotherms of three types of reinforced aerogels along with their pore size distributions are also shown in Fig. 8a and b, respectively. The specific surface areas and the pore size distributions were evaluated from the adsorption and desorption branches of the isotherms applying the Brunauer-Emmett-Teller (BET) and Barrett-Joyner-Halenda (BJH) methods, respectively. It was found that the isotherms of the samples were of type IV, according to the IUPAC classification, which is a typical profile for mesoporous materials recognized by their characteristic hysteresis loop. The decrease in adsorption value for whole reinforced aerogels is due to the fact that the pore structure of aerogel is lost/closed by the cross-linking with polymer. The results also show that the micro and mesoporosities are also significantly influenced by the underlying inorganic silica structures. For instance, the reinforced aerogels $B z \_10 \_R \_2$, despite the higher extent of polymerization on their surfaces (higher than the reinforced aerogel B_40_R_2, confirmed by ${ }^{13} \mathrm{C}$ NMR), show relatively higher adsorption volumes and, consequently, higher specific surface areas. As explained by Loy et al. this is probably due to the rigid nature of the aryl spacer, which allows less dimensional shrinkage of the silica skeleton and, therefore, less collapse of the pores occurs [29].

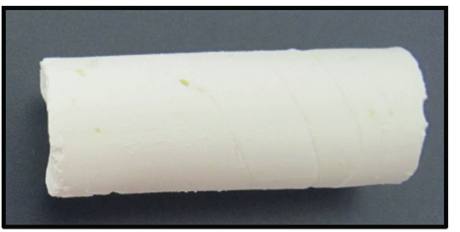

b) X-aerogel: $\mathrm{Nb} \mathrm{R} 2$

a) X-aerogel: $\mathrm{Nb} \_\mathrm{R} \_0.3$
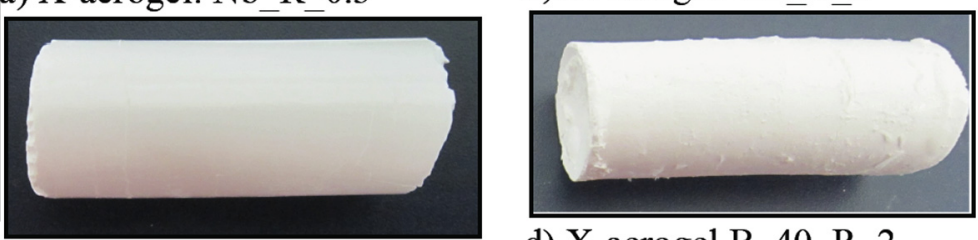

d) X-aerogel B_40_R_2

c) X-aerogel: B_40_R 0.3
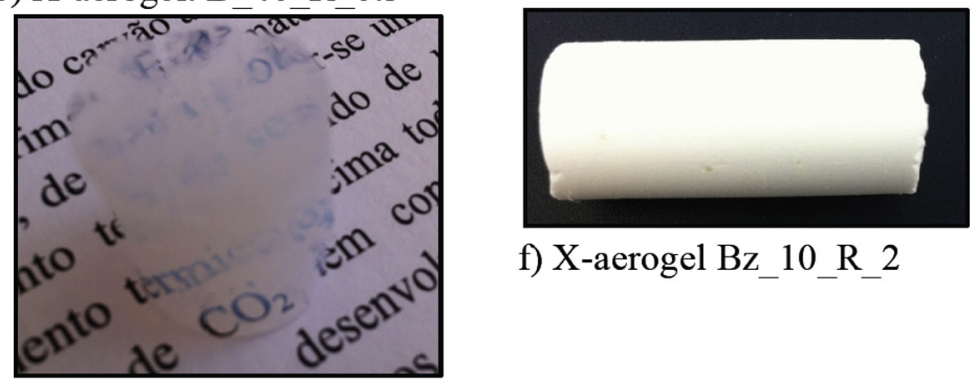

f) X-aerogel Bz 10 R 2

e) X-aerogel $\mathrm{Bz} 10 \mathrm{R} \quad 0.3$

Fig. 7. Photographs of some of selected tri-methacrylate reinforced silica aerogel monoliths. $(\mathrm{X}=$ cross-linked). 

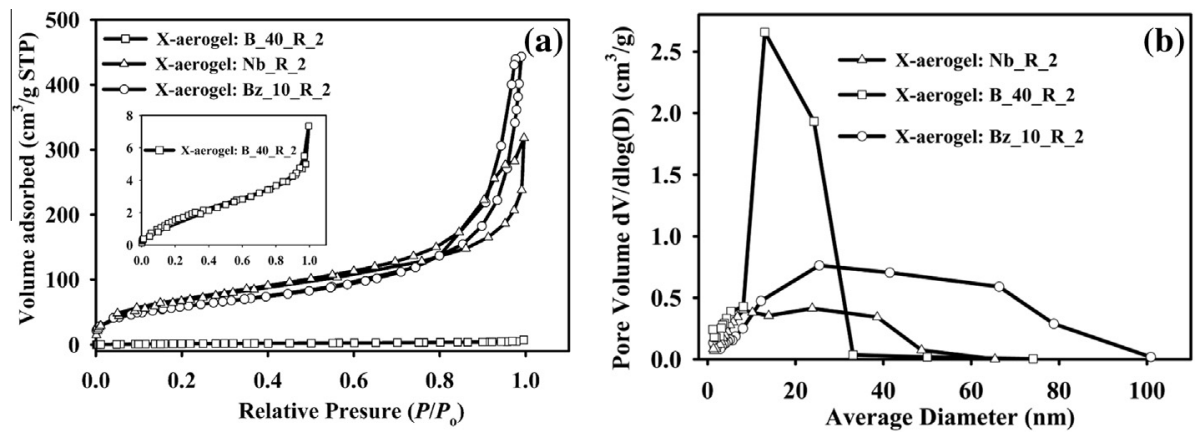

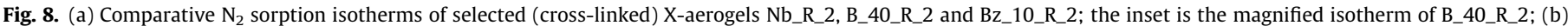
BJH pore size distributions from the desorption branches of the isotherms for cross-linked aerogels Nb_R_2, B_40_R_2 and Bz_10_R_2.

As indicated in Table 5, in the reinforced aerogels, the size of the pores decreases with cross-linking as the pores get gradually filled by polymer. Therefore, the average pore diameter of native aerogel samples generally is larger than pore diameters of their corresponding reinforced aerogels. Fig. $8 \mathrm{~b}$ indicates that the majority of the pores of the reinforced samples fall in the mesopores region, with relatively few micropores. Although the most part of microporosity is lost during the reinforcing process for aerogels made with $10 \mathrm{~mol} \%$ of Si from aryl bridged bis-silane, the diameter of mesopores (peak) increases to $13.1 \mathrm{~nm}$, due to the rigid nature of aryl bridges and, then, probably to less shrinkage of aerogels (specially at $R=2$ ) during cross-linking and drying.

For further elaboration in terms of microstructure of the prepared aerogels, we also observed the scanning electron micrographs (SEM) of the selected samples. Fig. 9a-i reveals that all aerogel networks appear as a 3D agglomerate of nanoparticles and the microstructures of the native nonreinforced and poly- mer-reinforced aerogels are not identical. The native TMOSderived aerogel network, Fig. 9a, has a more closed packed arrangement of the secondary silica particles with few nanometers size and high percentage of porosity. The incorporation of the alkyl-bridged precursor ( $40 \mathrm{~mol} \%$ of $\mathrm{Si}$ ), Fig. 9b, leads to a network with more open structure and larger pores sizes. The network of the nonreinforced BTESB-derived aerogels also shows a uniform arrangement of the secondary silica particles and a regular distribution of their mesoporosities, which was already confirmed by gas adsorption porosimetry.

In the aerogels that are cross-linked with polymer $(R=2)$, regardless of the type of the underlying silica network, the microstructure patterns change and the network appears more collapsed and dense - Fig. 9c, f and i. In these types of aerogel, the surface of silica is subjected to higher extent of polymerization, which resulted in silica aerogels with increased sizes of secondary silica particles as well as the significant loosing of fine pore structures.

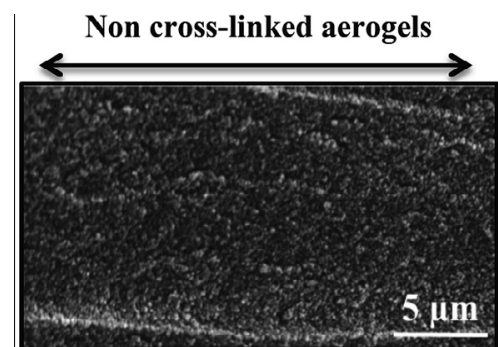

a) Plain TMOS: $0.24 \mathrm{~g} / \mathrm{cm}^{3}, 854 \mathrm{~m}^{2} / \mathrm{g}$, $93 \%$ porous

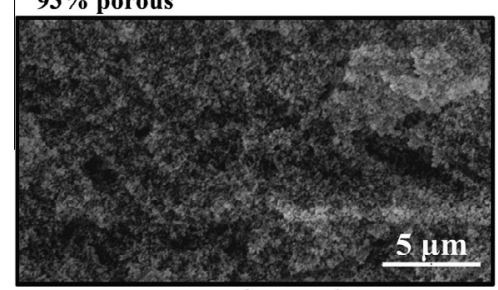

d) B 40: $0.185 \mathrm{~g} / \mathrm{cm}^{3}, 203 \mathrm{~m}^{2} / \mathrm{g}$, $85 \%$ porous

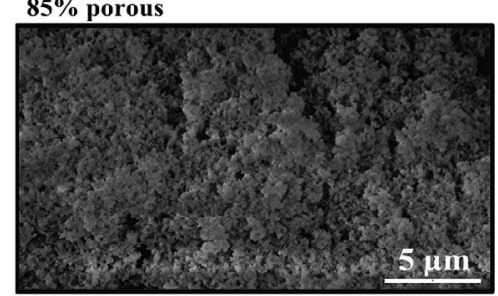

g) $B z \_10: 0.145 \mathrm{~g} / \mathrm{cm}^{3}, 719 \mathrm{~m}^{2} / \mathrm{g}$, $91 \%$ porous

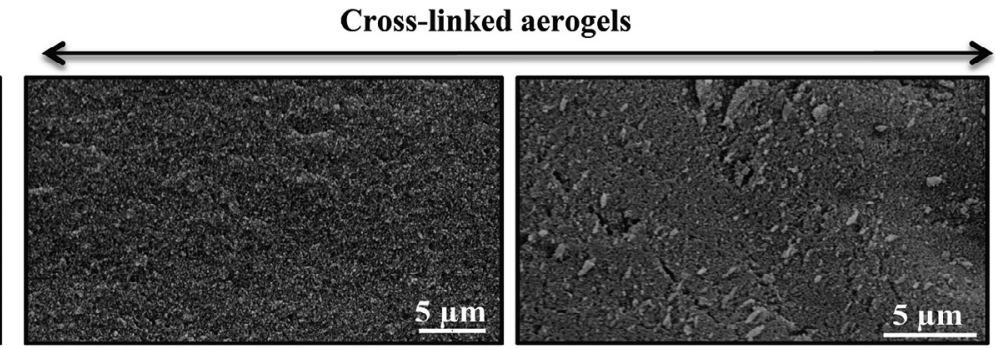

b) Nb_R_0.3: $0.173 \mathrm{~g} / \mathrm{cm}^{3}, 481 \mathrm{~m}^{2} / \mathrm{g}$, $86 \%$ porous

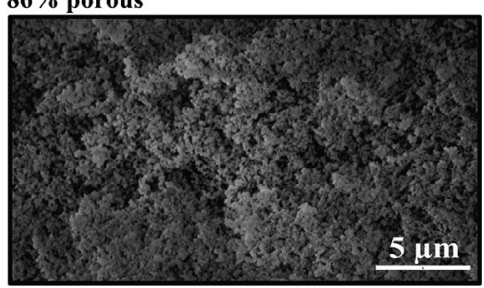

c) Nb_R_2: $0.290 \mathrm{~g} / \mathrm{cm}^{3}, 178 \mathrm{~m}^{2} / \mathrm{g}$, $77 \%$ porous

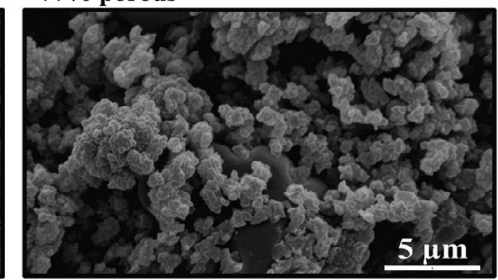

e) B_40_R_0.3: $0.22 \mathrm{~g} / \mathrm{cm}^{3}, 249 \mathrm{~m}^{2} / \mathrm{g}$, $87 \%$ porous

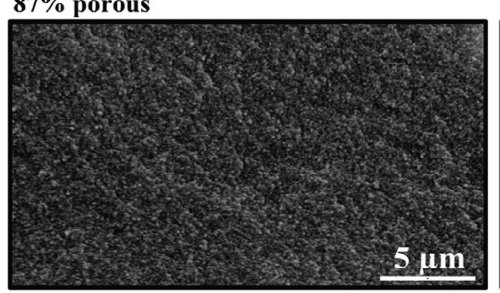

f) B 40 R 2: $0.39 \mathrm{~g} / \mathrm{cm}^{3}, 7.02 \mathrm{~m}^{2} / \mathrm{g}$ $71 \%$ porous

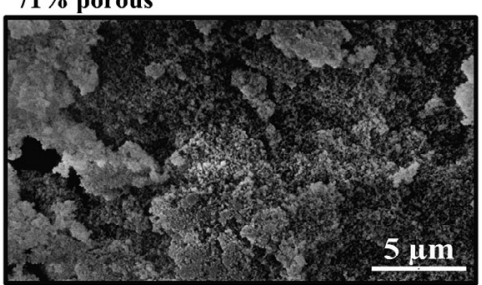

h) Bz_10_R_0.3: $0.145 \mathrm{~g} / \mathrm{cm}^{3}, 710 \mathrm{~m}^{2} / \mathrm{g}$, i) Bz_10_R_2: $0.249 \mathrm{~g} / \mathrm{cm}^{3}, 208 \mathrm{~m}^{2} / \mathrm{g}$, $89 \%$ porous $\quad 86 \%$ porous

Fig. 9. Scanning electron microscopy images of selected nonreinforced and reinforced aerogels. 
This effect is not so notable in the reinforced aerogels with less polymer $(R=0.3)$ - Fig. $9 \mathrm{~b}$, e and h. In fact, enhancing the crosslinker concentration from $R=0.3$ to $R=2$ leads to large number of silica surface methacrylate groups to react with the cross-linker and, then, causes pronounced differences in terms of the network appearance.

For aerogels without alkyl or aryl bridges in their inorganic underlying silica structures (Fig. 9b and c), increasing the crosslinker leads to a more compact structure with loss of the microporosity of the aerogel. But, overall, the concentration of crosslinker does not cause a marked difference in the microstructure appearance of this type of aerogel. Instead, increasing the crosslinker concentration for both type of BTMSH and BTESB-derived aerogels, as shown in Fig. 9e, $\mathrm{f}, \mathrm{h}$ and $\mathrm{i}$, respectively, leads to a pronounced effect in terms of secondary silica particle sizes and porosity arrangements. Indeed, the aerogels containing bridged precursors, in higher cross-linker concentration, possess larger clusters of silica nanoparticles with higher extent of macroporosity in the network and some loss of their micro and mesoporosity.

The porous texture of some selected samples is also well illustrated in Fig. 10a-c, which shows the transmission electron microscopy (TEM) micrographs of BTMSH and BTESB based aerogels as well as for an aerogel without bridged bis-silane in its structure. The TEM images for aerogel samples show a porous interconnected dendritic-type network structure, similar in nature to the one commonly observed in conventional silica aerogels [37]. The average size of individual (secondary) particle appears to be less than $10 \mathrm{~nm}$ for the aerogel without bis-silane. The introduction of BTESB and BTMSH bis-silanes to the silica structure leads to an increase in the average size of secondary particles of the order of 20 and $50 \mathrm{~nm}$, respectively. The inset of magnified section of each image well illustrates the pearl necklace arranging the semispherical connected silica secondary particles, which are composed by silica primary nanoparticles with an average size in the order of $\sim 1 \mathrm{~nm}$, as suggested also elsewhere [38]. However,
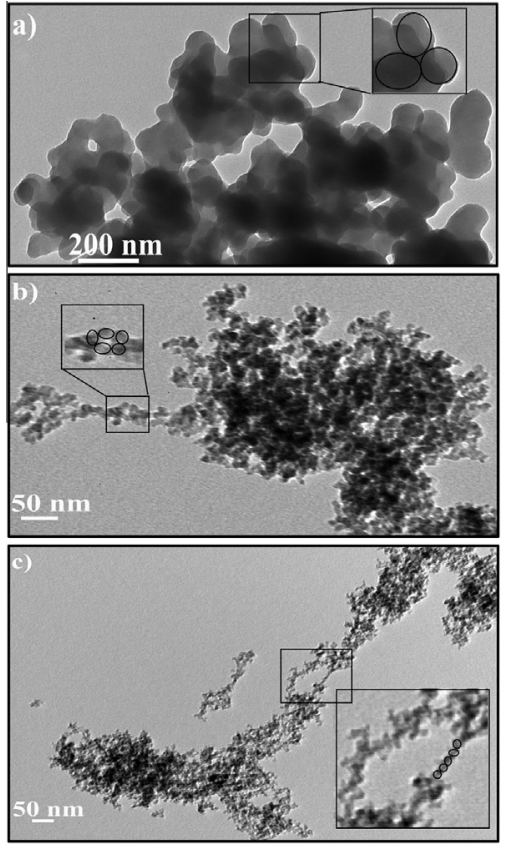

Fig. 10. TEM micrographs of selected (cross-linked) X-aerogels: (a) B_40_R_2, (b) $B z \_10 \_R \_2$, and, (c) Nb_R_2.

the secondary particles aggregated and make larger size clusters of about 200, 100 and less than $100 \mathrm{~nm}$ for reinforced aerogels B_40_R_2, Bz_10_R_2 and B_0_R_2, respectively.

\subsection{Thermal stability}

Thermogravimetric analysis (TGA) and simultaneous TG/DSC thermal analysis were conducted from ambient temperature to $600{ }^{\circ} \mathrm{C}$. The native TMOS-derived aerogel loses up to $\sim 9 \%$ of its
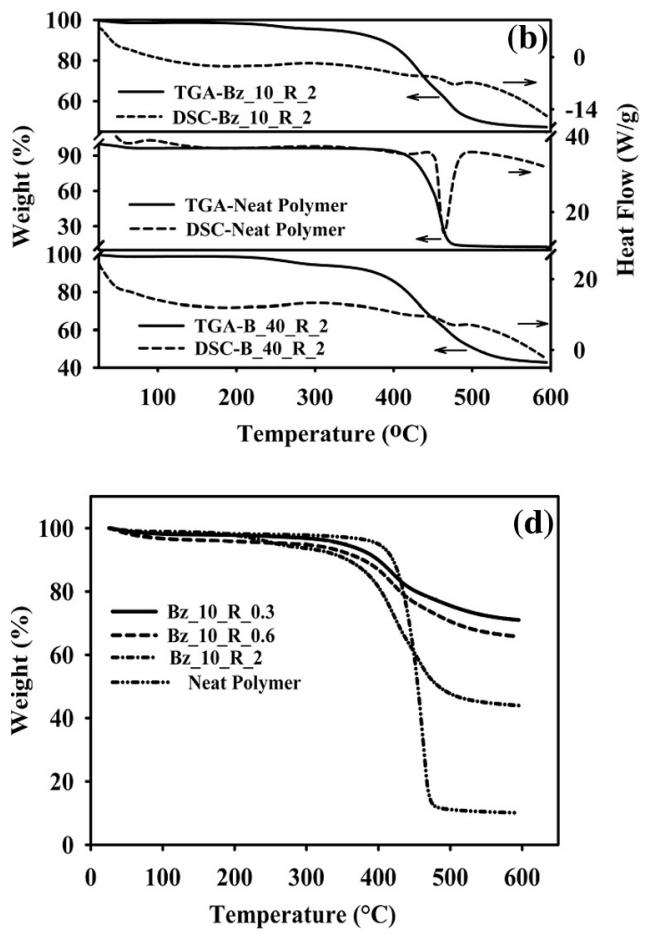

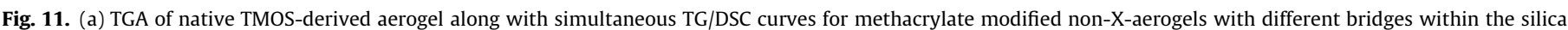

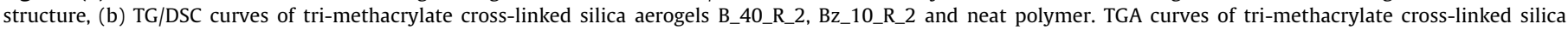
aerogels containing (c) $40 \mathrm{~mol} \%$ of $\mathrm{Si}$ from BTMSH and (d) $10 \mathrm{~mol} \%$ of Si from BTESB with different $R$ values, (heating rate: $\left.10{ }^{\circ} \mathrm{C} / \mathrm{min}\right)(\mathrm{X}=\mathrm{cross}-\mathrm{linked})$. 
weight at $73^{\circ} \mathrm{C}$ due to the evaporation of physically adsorbed water - Fig. 11a. This mass loss could also be implied for the loss of the $\mathrm{OH}$ groups at the network ends. In this figure, the simultaneous TG/DSC curves indicate that B_40 loses $4 \%$ of weight at $67{ }^{\circ} \mathrm{C}$ and $\mathrm{Bz} \_10$ loses $<1 \%$ of weight at $73{ }^{\circ} \mathrm{C}$, due the evaporation of adsorbed water in the network. These weight losses are accompanied by the endothermic peaks in the DSC curves at the same temperature for both samples. The observed adsorbed water mass losses indicate the ability of the TMOS-derived aerogels to retain adsorbed water throughout processing and, more importantly, can elucidate about the increase in the degree of hydrophobicity of the final aerogels when alkyl and aryl bridges are incorporated in their microstructures. Further mass losses take place at $496{ }^{\circ} \mathrm{C}$ due to the pyrolysis of the hexyl and silica surface methacrylate groups, for B_40, and at $392{ }^{\circ} \mathrm{C}$ due to the pyrolysis of aryl groups and silica surface methacrylate groups, for $\mathrm{Bz}-10$. The small endothermic peaks at $518{ }^{\circ} \mathrm{C}$ for $\mathrm{B}_{-} 40$ and at $425^{\circ} \mathrm{C}$ for Bz_10 confirm the thermal decomposition of the organic content inside of these aerogels.

The tri-methacrylate cross-linked B_40_R_2 aerogel loses all of their cross-linker and hexyl groups at $392^{\circ} \mathrm{C}$, being slightly less stable than the neat polymer that decomposes at $\sim 439^{\circ} \mathrm{C}-$ Fig. 11b. The DSC curves indicate that these mass losses are accompanied by a small endothermic peak at $477^{\circ} \mathrm{C}$, for B_40_R_2, and a sharp and intense peak at $464{ }^{\circ} \mathrm{C}$, for the neat polymer. In the trimethacrylate cross-linked Bz_10_R_2 aerogels, the decomposition of polymer and aryl bridges occurs at $394{ }^{\circ} \mathrm{C}$ along with a slight endothermic peak at $476{ }^{\circ} \mathrm{C}$. In these composites, the incorporation of aryl bridges leads to more stability of the aerogel composite compared to the BTMSH contained aerogels.

In summary, the TG/DSC studies are describing that the aerogel material absorbs heat during the observed mass losses. In other words, basically, the chemical reactions that happen in these aerogel insulating materials during the heating process are endothermic processes [39].

After assigning the weight loss contributions of the underlying silica at non-cross-linked aerogel, from Fig. 11a, the cross-linker weight loss contributions at Fig. 11c and d can be obtained by subtracting these values from the overall weight loss of the aerogel composite. Therefore, cross-linker contributions for the crosslinked BTMSH contained aerogels with $R$ ratios of $0.3,0.6$ and 2 are $8.65 \%, 12.38 \%$ and $23.42 \% \mathrm{w} / \mathrm{w}$ (Fig. 11c), respectively. This observation is in good agreement with increase in the bulk density and decrease in the specific surface area of this type of aerogels upon increasing cross-linker concentration.

The aryl groups, also, due to their intrinsic rigidity, and to some extent less steric hindrance of the aerogel structure, favour the accessibility of the monomer to the surface methacrylate groups. Therefore, polymer content in these composites is $20.23 \%, 23.32 \%$ and $31.66 \% \mathrm{w} / \mathrm{w}$ for aerogels with $R$ ratios of $0.3,0.6$ and $2-$ Fig. 11d, respectively, which shows higher introduction of the tri-methacrylate cross-linker in the aerogel than for the case in which BTMSH is used.

In analogy with recent arguments that have been given by Ilhan et al. [40] and Meador et al. [41], for epoxy and poly styrene reinforced aerogels, the average number of monomer units $\left(N_{\mathrm{t}}\right)$ in the tri-methacrylate cross-linked aerogel samples can be calculated by Eq. (2)..

$N_{t}=\frac{\rho_{\mathrm{b}, \text { cross-linked }}-\rho_{\mathrm{b}, \text { native }}}{M W_{\text {monomer }} \times S_{\text {cross-linked }} \times \rho_{\mathrm{b}, \text { cross-linked }}} \times \frac{1}{10^{-6}}$

where $S$ is the BET surface area, $\rho_{\mathrm{b}}$ is the bulk density and assuming that the monolayer coverage with a small molecule of monomer requires $10^{-6} \mathrm{~mol} \mathrm{~m}^{-2}$.

For tri-methacrylate cross-linked aerogel samples, including $0 \%$ of bis-silanes, $40 \mathrm{~mol} \%$ of Si from BTMSH and $10 \mathrm{~mol} \%$ of Si from BTESB precursors, at $R=2$, a typical polymer chain contains 3.2, 1.7 and 2.5 monomer units, respectively. These values are consistent with ${ }^{13} \mathrm{C}$ NMR and TGA results, which indicate that the extent of polymerization is relatively low for the cross-linked BTMSHderived aerogel.
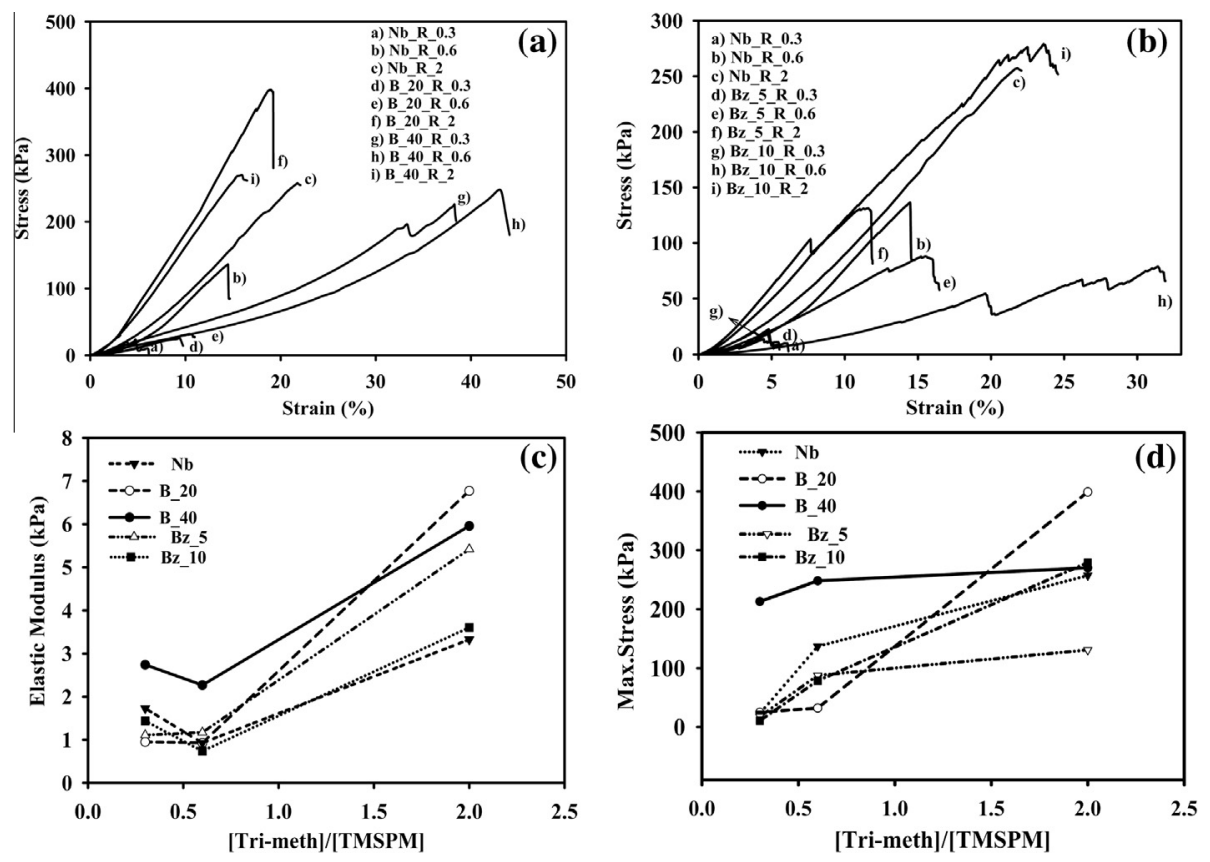

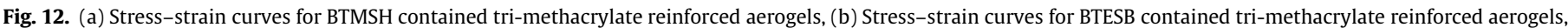

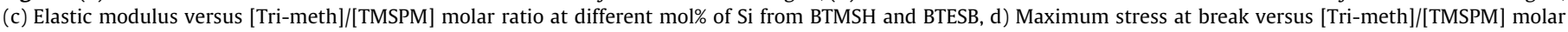
ratio at different mol\% of Si from BTMSH and BTESB. 

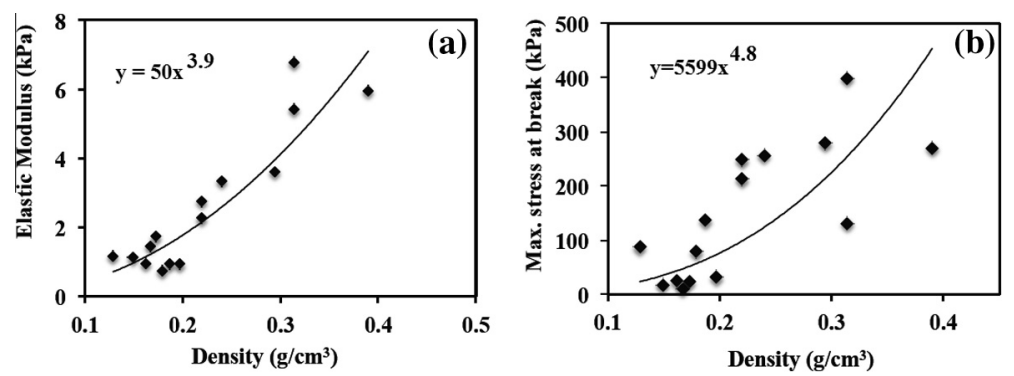

Fig. 13. (a) Power law dependency between elastic modulus and bulk density, (b) Power law dependency between maximum strength at break and bulk density.

\subsection{Mechanical and thermal conductivity properties}

The stress-strain curves obtained from compression tests to the reinforced and nonreinforced aerogels are shown on the Fig. 12a and $b$. The elastic modulus for each curve is calculated from the slope of data near the origin (slope of initial linear part of stressstrain curves) - Fig. 12c. The maximum stress at break of each aerogel is indicated in Fig. 12d. As can be seen from these figures, and data from Table 2, the maximum stress at break is improved for cross-linked aerogels but the modulus is slightly higher for the reinforced samples over their nonreinforced counterparts. The polymer-reinforced aerogels have as much as one order of magnitude higher maximum strength at break than their nonreinforced counterparts, indicating that the cross-linker indeed enhances their mechanical strength.

Among the reinforced aerogels made by $0-40 \mathrm{~mol} \%$ of $\mathrm{Si}$ from BTMSH, the aerogel with $20 \mathrm{~mol} \%$ and $R=2$ has the highest strength and elastic modulus. The higher strength values for this aerogel is probably due to a higher extent of cross-linking on the silica surface than the aerogel made with $40 \mathrm{~mol} \%$ of $\mathrm{Si}$ from BTMSH. As it was noted before, based on the ${ }^{13} \mathrm{C}$ NMR results, a higher percentage of BTMSH leads to a higher steric hindrance in the aerogel structure, which hinders the accessibility of the cross-linker to the silica surface functionality.

For the aerogels made using the aryl bridged precursor (BTESB), the elastic modulus of the aerogel prepared with $5-10 \mathrm{~mol} \%$ of $\mathrm{Si}$ from BTESB generally decreases with increasing percentage of BTESB. Additionally, the reinforced aerogel made with $10 \mathrm{~mol} \%$ of Si from BTESB and $R=2$, due the higher extent of polymerization in its surface, has a maximum strength at break slightly higher than the aerogel containing $40 \mathrm{~mol} \%$ of Si from BTMSH with the same $R$ value.

Fricke et al. [42] and Pekala et al. [43] presented the relation between mechanical properties (e.g., Young's modulus (E) or maximum strength etc.,) of silica aerogels and their bulk density $\left(\rho_{\mathrm{b}}\right)$ as power law relationship $E \sim \rho_{\mathrm{b}}^{\alpha}$. Therefore, according to this scaling law, the most straightforward methods of mechanical reinforcing of silica aerogels result in increasing the density and therefore increasing the thermal conductivity [44-46]. This is caused by the increase of the total amount of material used for the production of the gel matrix, due to the need of increasing the total number of connection points within the silica aerogel.

The graphs of the power law dependency between the elastic modulus and bulk density, and between the maximum stress at break and bulk density for all tri-methacrylate reinforced aerogels are shown in Fig. 13a and b. The power law exponent between the elastic modulus and bulk density for silica aerogels, without organic part, is reported to be 3 [47]. It is also reported that this exponent strongly depends on the synthesis route and connectivity between the secondary silica particles [46]. The power law exponent for polymer-reinforced silica aerogels is higher due to the conformal coating of the silica aerogel and reinforcement of the silica backbone by increasing the network connectivity between secondary silica particles.

The method of least-squares approach was used in this study to approximate the exponent of power law for the obtained reinforced aerogels. As shown in Fig. 13a, the power law dependency between the elastic modulus and the bulk density of the aerogels has an exponent of approximately 3.9. This value is comparable with those reported for the power law relationship between the modulus and density for tri-isocyanate reinforced silica with dipropyl amine linking groups from bis(trimethoxysilylpropyl)amine (BTSMPA) $([\alpha]=4.5)[48]$. Similar to the previous studies [34] [48] in which flexible alkyl bridges of bis-silanes contribute to the network connectivity, in the present work, the hexyl and aryl bridging groups from BTMSH and BTESB provide connections within the network. The obtained exponent for the power law relationship between the modulus and density is in agreement with the reported values by Nguyen et al. [48], which applied the tri-isocyanate cross-linker with molecular structure similar to that of the cross-linker used in the present work.

The maximum stress at break (Fig. 13b) for the reinforced aerogels shows a higher influence of the power law dependency from polymer reinforcement. In this case, the exponent $[\alpha]$ is 4.8 , higher than the reported values by Nguyen et al. $[\alpha]=4.3$, for their reinforced aerogels [48]. The higher value of this exponent for the tri-methacrylate cross-linked aerogels in this study is probably due to the higher structure variation possible in this system, i.e., the fact that the amount of the total silicon concentration, fraction of silicon derived from TMSPM and BTMSH/BTESB, amount of cross-linker and mechanism of cross-linking all contribute to the density, modulus and maximum stress in different ways.

Aerogels, due to their vast internal empty space, generally exhibit low thermal conductivities and, in that regard, an obvious application is in thermal insulation $[1,35]$.

As shown in Fig. 14 and Table 2, the thermal conductivity of reinforced aerogels is higher than the thermal conductivity of nonreinforced aerogels (Table 3 ), and it increases with the increasing

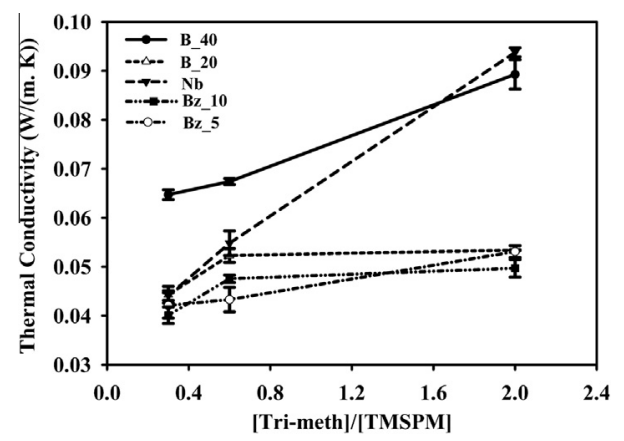

Fig. 14. Thermal conductivity of reinforced and nonreinforced aerogels with different underlying silica structures. 
in the cross-linker concentration and, consequently, with the increasing in the bulk density. The thermal conductivity of the aerogel without bridged precursors, at maximum concentration of the cross-linker, is higher than for those containing $\mathrm{Si}$ from BTMSH and BTESB within their structure. As it was noted before, this is due to the higher extent of polymerization that occurs in this type of aerogel without bis-silane precursors ( $0 \%$ bis-silane, $R=2$ ), which leads to higher thermal conductivity $(\mathrm{TC}=0.094 \pm 0.005)$ than the aerogel containing $40 \mathrm{~mol} \%$ of Si from BTMSH and $R=2$, with a TC value of $0.084 \pm 0.002$.

The thermal conductivity of the aerogel made with 5-10 mol\% of Si from BTESB is far less (TC $=0.050 \pm 0.002$, for $10 \mathrm{~mol} \%$ BTESB, $R=2$ ) than for other aerogels made with BTMSH or without bissilane precursors with comparable densities and mechanical strength. The lower thermal conductivity can be explained by open structure of aerogel due the high extent of porosity or volume (confirmed by porosimetry) compared to the other type of aerogels.

The thermal transfer in porous media like silica aerogels is conducted by three pathways: (i) solid transfer, which is the heat transfer through the chain of primary particles forming the solid silica network; (ii) thermal radiation; (iii) heat transfer by gaseous molecules present in the porous structure of the aerogel. In the cross-linked aerogels, due to the additional mass inserted by the reinforcement agents and bis-silane precursors, an increase in the density and, consequently, in the solid or backbone thermal conductivity of the aerogel is observed. The increase of Si mol\% from BTESB in the range of $5-10 \mathrm{~mol} \%$ causes an improvement in the thermal conductivity, but further increasing over $10 \mathrm{~mol} \%$ likely leads to rigid and non-elastic properties which are not favorable in terms of mechanical properties. The pore sizes of BTESBderived and nonreinforced aerogels were found to be larger than those of aerogels made with and without BTMSH. The large pores sizes often lead to large pore volumes and, thus, lead to large porosity. Large porosity, in turn, favours low thermal conductivity.

\section{Conclusions}

The incorporation of alkyl and aryl bridges of bis-silane precursors in the underlying silica of aerogels along with cross-linking of the silica surface functionality with tri-methacrylate cross-linker is examined. In this work, the synthesis process was simplified by eliminating the diffusion step of the monomer into the silica network, and aerogels with low densities along with improvement in the mechanical strength and thermal insulation performance have been obtained. Although moderate improvement in terms of the elastic modulus for all aerogels has been achieved, still more than one order of magnitude improvement in the compression strength (up to $400 \mathrm{kPa}$ ) has been attained. The mechanical strength improvement is somewhat limited by the aerogel's bulk density $\left(\rho_{\mathrm{b}}\right)$ of $\approx 0.13$ to $0.39 \mathrm{~g} \mathrm{~cm}^{-3}$, which is far below the values of the previously reported reinforced aerogels with $\rho_{\mathrm{b}}>0.4 \mathrm{~g} \mathrm{~cm}^{-3}$ [11] [25-28].

Notably, in terms of BTESB derived aerogels the surface area and extent of porosity even after cross-linking was quite high, confirming a high contribution of the underlying silica on the mesoporous structure of the aerogel. When compared to the other types of aerogel, the reinforced BTESB based aerogel, despite of higher extent of cross-linking (proved by TGA and ${ }^{13} \mathrm{C} N M R$ ), shows quite ordered and larger mesopores, leading to further improvement in terms of thermal insulation performance. In fact, the introduction of the aryl bridges of BTESB precursor in the silica structure of the reinforced aerogels resulted in thermal conductivity values lower than $0.04 \mathrm{~W} \mathrm{~m}^{-1} \mathrm{~K}^{-1}$, which is less than the values found for epoxy, styrene and isocyanate reinforced aerogels, reported so far [25].

It is also worthy to note that the aerogel made by $10 \mathrm{~mol} \%$ of $\mathrm{Si}$ derived from BTESB is at the same time stiffer and stronger than those made by incorporation up to $40 \mathrm{~mol} \%$ of Si from BTMSH, with comparable density values. However, a remarkable improvement in the mechanical strength of BTMSH based aerogel was also achieved, even at low concentration of cross-linker $(R=0.3)$, with little changes in the density, over the non-cross-linked counterparts.

In summary, the strong silica aerogels with improved mechanical and thermal insulation performance developed here can be robust thermal insulator candidates for different potential aerospace applications.

\section{Acknowledgements}

The research leading to these results has received funding from the European Union Seventh Framework Programme (FP7-MC-ITN) under grant agreement No. 264710. The authors would like to thank the Directorate-General for Science, Research and Development of the European Commission for financial support of the research.

\section{References}

[1] A.C. Pierre, G.M. Pajonk, Chem. Rev. 102 (2002) 4243-4265.

[2] M.L.N. Perdigoto, R.C. Martins, N. Rocha, M.J. Quina, L. Gando-Ferreira, R. Patrício, L. Durães, J. Colloid Interface Sci. 380 (2012) 134-140.

[3] A.V. Rao, N.D. Hegde, H. Hirashima, J. Colloid Interface Sci. 305 (2007) 124-132.

[4] M. Adebajo, R. Frost, J. Kloprogge, O. Carmody, S. Kokot, J. Porous Mater. 10 (2003) 159-170.

[5] J.W. Long, K.E. Swider Lyons, R.M. Stroud, D.R. Rolison, Electrochem. Solid-State Lett. 3 (2000) 453-456.

[6] D.A. Ward, E.I. Ko, J. Ind. Eng. Chem. Res. 34 (1995) 421-433.

[7] C.T. Wang, C.L. Wu, I.C. Chen, Y.H. Huang, Sens. Actuators, B 107 (2005) 402 410.

[8] M.T. Guise, B. Hosticka, B.C. Earp, P.M. Norris, J. Non-Cryst. Solids 285 (1995) 317-322.

[9] L.W. Hrubesh, J. Non-Cryst. Solids 225 (1998) 335-342.

[10] M. Schmidt, F. Schwertfeger, J. Non-Cryst. Solids 225 (1998) 364-368.

[11] J.P. Randall, M.A.B. Meador, S.C. Jana, ACS Appl. Mater. Interfaces 3 (2011) 613 626.

[12] L. Durães, S. Nogueira, A. Santos, C. Preciso, J. Hernandez, A. Portugal, Flexible silica based xerogels and aerogels for spatial applications, in: E. Ferreira (Ed.) Proc. of the 10th International Chemical and Biological Engineering Conference-CHEMPOR, Department of Biological Engineering of University of Minho, Braga, 2008, pp. 563.

[13] L. Durães, M. Ochoa, A. Portugal, N. Duarte, J.P. Dias, N. Rocha, J. Hernandez, Adv. Sci. Tech. 63 (2010) 41-46.

[14] M. Koebel, A. Rigacci, P. Achard, J. Sol-Gel. Sci. Technol. 63 (2012) 315-339.

[15] H. Maleki, L. Durães, A. Portugal, J. Non-Cryst. Solids 385 (2014) 55-74.

[16] A.V. Rao, D. Haranath, Micropor. Mesopor. Mater. 30 (1999) 267-273.

[17] A.V. Rao, S.D. Bhagat, H. Hirashima, G.M. Pajonk, J. Colloid Interface Sci. 300 (2006) 279-285.

[18] D.Y. Nadargi, S.S. Latthe, H. Hirashima, A.V. Rao, Micropor. Mesopor. Mater 117 (2009) 617-626.

[19] H. Guo, B.N. Nguyen, L.S. Mccorkle, B. Shonkwilerb, M.A.B. Meador, J. Mater. Chem. 19 (2009) 9054-9062.

[20] N. Leventis, H. Lu, M.M. Koebel (Eds.), Aerogel Handbook, Springer, 2010, pp. $252-285$.

[21] N. Leventis, H. Lu, M.M. Koebel (Eds.), Aerogel Handbook, Springer, 2010, pp. 315-334.

[22] Y. Duan, S.C. Jana, B. Lama, M.P. Esp, Langmuir 29 (2013) 6156-6165

[23] Y. Duan, S.C. Jana, A.M. Reinsel, B. Lama, M.P. Espe, Langmuir 28 (2012) 15362 15371.

[24] M.A.B. Meador, S.L. Vivod, L. Mccorkle, D. Quade, R.M. Sullivan, L.N. Ghson, Clark, L.A. Capaclona, J. Mater. Chem. 18 (2008) 1843-1852.

[25] N. Leventis, Acc. Chem. Res. 40 (2007) 874-884.

[26] N. Leventis, A. Sadekar, N. Chandrasekaran, C. Sotiriou-Leventis, Chem. Mater 22 (2010) 2790-2803.

[27] M.A.B. Meador, L.A. Capadona, L. Mccorkle, D.S. Papadopoulos, N. Leventis, Chem. Mater. 19 (2007) 2247-2260.

[28] D.J. Boday, P.Y. Keng, B. Muriithi, J. Pyun, D.A. Loy, J. Mater. Chem. 20 (2010) $6863-6865$.

[29] D.A. Loy, G.M. Jamison, B.M. Baugher, A.S. Myers, R.A. Assink, K.J. Shea, Chem. Mater. 8 (1996) 656-663.

[30] K.J. Shea, D.A. Loy, Chem. Mater. 13 (2001) 3306-3319. 
[31] D.A. Loy, K.J. Shea, Chem. Rev. 95 (1995) 1431-1442.

[32] M.A.B. Meador, B.N. Nguyen, D. Quade, S.L. Vivod, ACS Appl. Mater. Interfaces 2 (2010) 2162-2168.

[33] S. Mulik, C. Sotiriou-Leventis, G. Churu, H. Lu, N. Leventis, Chem. Mater. 20 (2008) 5035-5046.

[34] B.N. Nguyen, M.A.B. Meador, M.E. Tousley, B. Shonkwiler, L. Mccorkle, D.A. Scheiman, A. Palczer, ACS Appl. Mater. Interfaces 1 (2009) 621-630.

[35] C.J. Brinker, G.W. Scherer, Sol-Gel Science: The Physics and Chemistry of SolGel Processing, Academic Press, 1990.

[36] K.J. Shea, D.A. Loy, O. Webster, J. Am. Chem. Soc. 114 (1992) 6701-6710.

[37] R.M. Stroud, J.W. Long, J.J. Pietron, D.R. Rolison, J. Non-Cryst. Solids 350 (2004) $277-284$.

[38] G. Zhang, A. Dass, A.-M.M. Rawashdeha, J. Thomas, J.A. Counsil, C. SotiriouLeventis, E.F. Fabrizio, F. Ilhan, P. Vassilaras, D. Scheiman, L. Mccorkle, A Palczer, J.C. Johnston, M.A.B. Meador, N. Leventis, J. Non-Cryst. Solids 350 (2004) 152-164.

[39] T. Xie, Y.-L. He, Z.-X. Tong, W.-X. Yan, X.-Q. Xie, Int. J. Heat Mass Transfer 68 (2014) 633-640.
[40] U.F. Ilhan, E.F. Fabrizio, L. Mccorkle, D.A. Scheiman, A. Dass, A. Palczer, M.A.B. Meador, J.C. Johnston, N. Leventis, J. Mater. Chem. 16 (2006) 30463054.

[41] M.A.B. Meador, E.F. Fabrizzio, F. Ilhan, A. Dass, G. Zhang, P. Vassilaras, J.C, Johnston, N. Leventis, Chem. Mater. 17 (2005) 1085-1098.

[42] J. Fricke, J. Non-Cryst. Solids 100 (1988) 169-173.

[43] R.W. Pekala, L.W. Hrubesh, T.M. Tillotson, C.T. Alviso, J.F. Poco, J.D. Lemay, MRS Symposium W: Scaling in Disordered Materials, Boston, Materials Research Society, Warrendale, pa, 1990.

[44] J. Fricke, A. Emmerling, J. Sol-Gel. Sci. Technol. 13 (1998) 299-303.

[45] J. Gross, J. Fricke, J. NanoStruct. Mater. 6 (1995) 905.

[46] T. Woignier, J. Reynes, A. Hafidialaoui, I. Beurroies, J. Phalippou, J. Non-Cryst. Solids 241 (1998) 45-52.

[47] R.W. Pekala, L.W. Hrubesh, T.M. Tillotson, C.T. Alviso, J.F. Poco, J.D. Lemay, Mater. Res. Soc. Symp. Proc. 207 (1991) 197-200.

[48] B.N. Nguyen, M.A.B. Meador, A. Medoro, V. Arendt, J. Randall, L. Mccorkle, B. Shonkwiler, ACS Appl. Mater. Interfaces 2 (2010) 1430-1443. 